\title{
HEALTH INSURANCE, LABOR SUPPLY, AND JOB MOBILITY: A CRITICAL REVIEW OF THE LITERATURE
}

\author{
Jonathan Gruber \\ Brigitte C. Madrian \\ Working Paper 8817 \\ http://www.nber.org/papers/w8817
NATIONAL BUREAU OF ECONOMIC RESEARCH
1050 Massachusetts Avenue
Cambridge, MA 02138
March 2002

Prepared for the "Research Agenda Setting Conference" held at the University of Michigan, July 8-10, 2001. We thank Catherine McLaughlin, Hilary Hoynes, Tom Buchmueller, and conference participants for helpful comments. Financial support from the Robert Wood Johnson is gratefully acknowledged. The views expressed herein are those of the authors and not necessarily those of the National Bureau of Economic Research.

(C) 2002 by Jonathan Gruber and Brigitte C. Madrian. All rights reserved. Short sections of text, not to exceed two paragraphs, may be quoted without explicit permission provided that full credit, including (C) notice, is given to the source. 
Health Insurance, Labor Supply, and Job Mobility:

A Critical Review of the Literature

Jonathan Gruber and Brigitte C. Madrian

NBER Working Paper No. 8817

March 2002

JEL No. I12, J32, J24

\begin{abstract}
This paper provides a critical review of the empirical literature on the relationship between health insurance, labor supply, and job mobility. We review over 50 papers on this topic, almost exclusively written in the last 10 years. We reach five conclusions. First, there is clear and unambiguous evidence that health insurance is a central determinant of retirement decisions. Second, there is fairly clear evidence that health insurance is not a major determinant of the labor supply and welfare exit decisions of low income mothers. Third, there is fairly compelling evidence that health insurance is an important factor in the labor supply decisions of secondary earners. Fourth, while there is some division in the literature, the most convincing evidence suggests that health insurance plays an important role in job mobility decisions. Finally, there is virtually no evidence in the literature on the welfare implications of these results. We present some rudimentary calculations which suggest that the welfare costs of job lock are likely to be modest. Our general conclusion is that health insurance has important effects on both labor force participation and job choice, but that it is not clear whether or not these effects results in large losses of either welfare or efficiency.
\end{abstract}

Jonathan Gruber

Massachusetts Institute of Technology

Department of Economics

50 Memorial Drive, E52-355

Cambridge, MA 02142-1347

and NBER

gruberj@mit.edu
Brigitte C. Madrian

University of Chicago

Graduate School of Business

1101 E. 58th Street

Chicago, IL 60637

brigitte.madrian@gsb.uchicago.edu 


\section{Health Insurance, Labor Supply, and Job Mobility: A Critical Review of the Literature}

\section{Introduction}

A distinctive feature of the health insurance market in the U.S. is that group insurance is available almost exclusively through the workplace, with very few pooling mechanisms available for insurance purchase outside of work. As a result, over ninety percent of the privately insured population currently obtains their insurance coverage through the workplace, either through their own employment or the employment of a family member (Employee Benefit Research Institute, 2000).

This restriction of health insurance purchase to the workplace setting has potentially quite important implications for the functioning of the U.S. labor market, along many dimensions. For example, the high level of health insurance costs, currently amounting to $6.7 \%$ of compensation (McDonnell and Fronstin, 1999), has been shown to impact wage, employment and hours determination in labor market equilibrium. ${ }^{1}$ Another important set of potential impacts is on labor supply and job mobility decisions. Given the high and variable level of health care costs for many workers, health insurance can be a key factor in the decision to work, to retire, to leave welfare, or to switch jobs.

The potential for important impacts of health insurance on labor supply and job mobility decisions has motivated a significant literature on this topic over the past decade. While there was virtually no work on these issues before 1990, in this article we review over 50 scholarly articles written in the ten years since. This literature is wide ranging in both substance and in empirical approach. Yet important commonalities exist which allow for a fairly comprehensive and rigorous review of the findings, allowing us a fairly clear assessment of what the past decade of work has taught us about health insurance, labor supply, and job mobility.

We have two primary conclusions from our critical literature review. First, this literature has gone far in one important direction, namely quantifying the importance of health insurance for labor supply and job choice decisions. As in all academic discourse, there is some

${ }^{1}$ See Gruber (2000) and Currie and Madrian (1999) for literature reviews. 
disagreement, but our reading of the evidence is that there is a fairly consistent case to be made that health insurance matters quite a bit for decisions such as whether to retire or to change jobs.

Our second conclusion, however, is that the literature has essentially failed to advance our knowledge along another critical dimension-the implications of these results. We know, for example, that individuals with health insurance who particularly value that insurance are less likely to leave those jobs than their counterparts who value it less. But we don't know whether this substantially reduces either economic growth or personal welfare. Given the importance of labor mobility in the U.S. economy, it seems likely that the welfare costs of such labor market distortions may be large. But there have been essentially no attempts to quantify them. Similar limitations exist with the literature on health insurance and labor supply.

In this paper, we provide an integrating framework for thinking about these literatures. We begin by providing a general model of health insurance and mobility that documents why "job lock," or insurance induced immobility, may arise; this model is easily applied as well to health insurance and labor supply decisions. We then provide a critical review of the exciting and large (almost exclusively empirical) literature that has arisen on these topics over the past decade. Finally, we conclude with a heuristic discussion of how one might think about the welfare implications of these findings. We do not in this paper provide direct evidence on welfare implications or even a rigorous framework for computing welfare costs. But we lay out the issues that must, and should, be tackled by those who will take on this important task.

\section{A Model of Employer-Provided Health Insurance and Labor Mobility}

In this section, we discuss a simple model that illustrates the notion that "job lock" might be an important concern. While the model focuses on mobility, it is easily extended to consider labor supply effects as well, as we discuss below. This section draws heavily on the model developed in Gruber (2000).

The very notion that health insurance is responsible for imperfections in the functioning of the U.S. labor market is somewhat curious. After all, health insurance is a voluntarily provided form of employee compensation. There is little discussion of the distortions to the labor market from cash wages. Why is health insurance different?

To see the difficulties introduced by health insurance in reality, it is useful to begin with a very stylized "pure compensating differentials" model (Rosen, 1986). We start with a highly stylized example in which there is no distortionary effect of health insurance on the labor market. We then relax the very strong assumptions that are required by this example in order to illustrate the source of distortions to mobility.

In this example, health insurance coverage consists of a binary, homogeneous good; individuals are either covered or not, and if covered have the exact same insurance plans. Insurance is perfectly experience rated at the worker level. That is, firms essentially purchase 
insurance on a worker-by-worker basis and are charged a separate premium for each worker. Jobs that offer health insurance feature a negative compensating wage differential. Moreover, each individual job (worker-firm match) can have its own compensation structure; firms can offer insurance to some workers and not others, and can pay lower wages to those workers whose insurance costs more.

We assume that individuals have preferences over wage compensation and health insurance:

$$
\mathrm{U}_{\mathrm{ij}}=\mathrm{U}\left(\mathrm{W}_{\mathrm{ij}}, \mathrm{H}_{\mathrm{ij}}\right)
$$

where $\mathrm{W}_{\mathrm{ij}}$ is the wage level of worker $\mathrm{i}$ at firm $\mathrm{j}$, and $\mathrm{H}_{\mathrm{ij}}$ is a binary indicator for insurance coverage of worker $\mathrm{i}$ at firm $\mathrm{j}\left(\mathrm{H}_{\mathrm{ij}}=1\right.$ or 0$)$. The (pre-compensating differential) wage rate for each worker/job match is equal to the worker's marginal product at that job.

Given these preferences, individuals will desire health insurance coverage if there is a compensating wage differential $\Delta \mathrm{W}_{\mathrm{ij}}$ such that:

$$
\mathrm{U}\left(\mathrm{W}_{\mathrm{ij}}-\Delta \mathrm{W}_{\mathrm{ij}}, 1\right)-\mathrm{U}\left(\mathrm{W}_{\mathrm{ij}}, 0\right)=\mathrm{V}_{\mathrm{ij}} \geq 0
$$

Suppose that there are a continuum of jobs in the economy, and that the labor market is perfectly competitive. Firms face identical worker-specific insurance price schedules; a given worker $\mathrm{i}$ incurs a cost of insurance $\mathrm{C}_{\mathrm{ij}}=\mathrm{C}_{\mathrm{i}}$ in whatever firm he works. In this world, firms will provide insurance to their workers if:

$$
\Delta \mathrm{W}_{\mathrm{ij}} \geq \mathrm{C}_{\mathrm{i}}
$$

As a result of perfect competition, firms will bid the compensating differential down to the level $\mathrm{C}_{\mathrm{i}}$. Thus, all workers covered by insurance will earn exactly:

(4) $\mathrm{W}_{\mathrm{ij}}-\Delta \mathrm{W}_{\mathrm{ij}}=\mathrm{W}_{\mathrm{ij}}-\mathrm{C}_{\mathrm{i}}$

on whatever job they hold.

In this simplified model, there is no real effect of health insurance on the labor market equilibrium. The introduction of health insurance simply leads to lower wages for workers who value that insurance at its cost or more. If individuals wish to change jobs, they can simply ask their new employer to provide them with insurance and lower their wage by $C_{i}$. Workers for whom $\mathrm{V}_{\mathrm{ij}}>0$ are earning rents from the fact that they value insurance at above its cost, but firms cannot extract those rents, since workers will be bid away by other employers who charge them the appropriate compensating differential. Most importantly, there is no inefficiency from health insurance: since workers will pay the same compensating differential $\mathrm{C}_{\mathrm{i}}$ wherever they work, they will choose the job with the highest level of wages $\mathrm{W}_{\mathrm{ij}}$. So workers will find the best jobspecific matches, regardless of their tastes for insurance. 
This highly stylized model is useful for illustrating the conditions necessary to generate no mobility effects of insurance. But reality departs from this model in at least two important ways. First, employers are constrained in their ability to freely set employee-specific compensation packages, offering insurance to some workers and not to others. The Internal Revenue Code gives favorable tax treatment to employer expenditures on health insurance only if most workers are offered an equivalent benefits package. Moreover, the costs of administering such a complicated benefits system would absorb much of the rents that workers would earn from its existence. And the problems of preference revelation in this context are daunting; it is difficult in reality to see how firms could appropriately set worker-specific compensating differentials. This departure implies that there will be match-specific rents for workers attached to particular jobs.

Second, employers differ dramatically in the underlying costs of providing health insurance. For example, the cost of insurance is much higher in small firms. There are enormous economies of scale in insurance purchase resulting from fixed costs in administration that must be paid for any size group. Large workplace pools also provide a means for individuals to purchase insurance without the adverse selection premium that insurers demand in the individual health insurance marketplace, since the unobservable components of health will average out in large groups. For smaller groups, on the other hand, there is the risk that insurance purchase is driven by the needs of one or two (unobservably) very ill employees, whose costs cannot possibly be covered by the premium payments of healthier workers. As the Congressional Research Service (1988) reports, the loading factor on insurance purchases by the very smallest groups (firms with less than 5 employees) is over $40 \%$ higher than that on very large groups (more than 10,000 employees), and the loading factor for individual insurance is even higher. Moreover, Cutler (1994) finds more dispersion in per worker health insurance premiums among small firms than among larger ones, which is consistent with greater adverse selection problems in the small group market.

More generally, Cutler (1994) documents that, even conditional on observable factors such as firm size and benefits package characteristics, there remains huge variation in insurance premiums across otherwise identical firms. This variation arises from both unobserved differences in the relationship between firm characteristics and insurance supply prices, and from heterogeneity in the workforce along health dimensions. This implies that workers may be unable to obtain health insurance on comparable terms across jobs.

As a result of these two features, there will be matching of particular workers and firms in labor market equilibrium: those workers who most desire health insurance coverage will work at firms offering insurance, and those firms who can provide that insurance most cheaply will offer it. In the extreme case of a perfectly competitive labor market, there will be a market-wide compensating differential $\Delta \mathrm{W}$. Workers will only work at firms offering insurance if their valuation of insurance is at least as great as this compensating differential, $\mathrm{V}_{\mathrm{ij}}>\Delta \mathrm{W}$. Firms will only offer insurance if the per worker cost of insurance to that firm, $\mathrm{C}_{\mathrm{j}}$, is less than the compensating differential, $\mathrm{C}_{\mathrm{j}}<\Delta \mathrm{W}$. This is the compensating differentials equilibrium described by Rosen (1986). As highlighted by his discussion, in equilibrium all of the workers 
whose valuation of insurance $\mathrm{V}_{\mathrm{ij}}$ is greater than $\Delta \mathrm{W}$ will be earning rents from working at a job with health insurance; similarly, all firms whose costs of insurance $\mathrm{C}_{\mathrm{j}}$ are below $\Delta \mathrm{W}$ will earn rents.

Adding these complications introduces the possibility of job lock. Suppose that an individual now holds job 0 , but would be more productive on job $1\left(\mathrm{~W}_{\mathrm{i} 1}>\mathrm{W}_{\mathrm{i} 0}\right)$. The cost of insurance to firm 1 is much higher, however $\left(\mathrm{C}_{1}>\mathrm{C}_{0}\right)$. This high cost might arise from a high loading factor, or from the fact that the firm has a relatively unhealthy workforce and is experience rated. As a result, firm 1 does not offer insurance; even though this insurance would attract worker $\mathrm{i}$, it will cost too much to provide for the rest of the workforce. And, most importantly, the insurance can't just be provided for worker i. As a result, if:

$$
\mathrm{U}\left(\mathrm{W}_{\mathrm{i} 0}-\Delta \mathrm{W}, 1\right)-\mathrm{U}\left(\mathrm{W}_{\mathrm{i} 1}, 0\right)>0
$$

then the worker will not switch jobs, even though he would be more productive on the new job. This is the welfare loss from job lock: productivity improving switches are not made.

Note that, in theory, firm 0 could extract the surplus from this worker, knowing that he will not move to firm 1. Full extraction of these rents would mean that there was no net "locking" of the employee into his job at firm 0 . The key question, of course, is the extent to which firms can discriminate in wages on the basis of the value of insurance.

There is a long literature on the incidence of health insurance costs which speaks to this question, and it is reviewed by others at this conference, as well as in Gruber (2000). That literature finds clear evidence that the costs of insurance are shifted to worker wages on average, at least in the medium to long run. And there is also evidence in Gruber (1994) and Sheiner (1999) cost shifting to broad demographic groups within the workplace, with relatively high cost groups (such as older workers or women of child-bearing age) receiving lower wages as a result. But there is no evidence to date that speaks to worker-specific shifting. In practice, full rent capture on a worker-by-worker basis seems unlikely, due to preference revelation and administrative difficulties. So long as pay discrimination by valuation of insurance doesn't occur on a person-by-person basis, there will be job lock.

It is important to note that this type of lock arises from any employee benefit for which there is differential valuation across workers, differential costs of provision across employers, and the inability to set worker-specific compensation packages (e.g. workplace safety, or the location of the firm). The key insight is that in these situations, a firm cannot offer the benefit just to the marginal worker whom it wishes to attract, leading to job-specific rents and job-lock. In practice, however, this effect is likely to be quite large for health insurance relative to other benefits, since both the variation in valuation across workers and the variation in costs of provision across firms are much higher than for other workplace amenities.

In theory, this problem only arises for workers considering switches from the sector providing insurance to the sector not providing insurance. But, even within the insurance 
providing sector, there may be job lock arising from the fact that health insurance coverage is not a homogenous good. For example, pre-existing conditions exclusions may leave the worker exposed to large medical costs if he switches to a new plan. There are also probationary periods for new coverage and (in the extreme) medical underwriting and the exclusion of costly new employees from insurance coverage. Job changers may also lose credit towards deductibles and out-of-pocket payment limits under their old plans, raising the out of pocket costs of medical care on a new job relative to an old one. In addition, health insurance is not a discrete choice but rather a continuum of policy features. The worker's current job may offer a wider range of insurance options that is not available at other jobs which offer insurance, making job switching unattractive, particularly if the worker is restricted (through a managed care plan) from using his preferred medical providers. Finally, the fact that insurance purchased in the individual market is very expensive, less comprehensive, and potentially not even available to very unhealthy applicants, also raises the costs of off-the-job search. All of these factors mitigate against leaving a job that currently has insurance even if the next job is likely to have insurance as well.

Although we have framed the preceding discussion around the specific issue of job mobility, the same model developed above can be applied to labor supply decisions as well. In this case, the choice for the worker is not between one job and another, but between employment and nonemployment, where the health insurance availability across these two states may possibly differ. For example, consider an older worker thinking about whether to retire. Even if his value of leisure is greater than his marginal product of labor, a less healthy older worker may be unwilling to retire from a job that offers health insurance if health insurance when not employed is either not available or prohibitively expensive. This is a form of "lock."

Retirement is not the only labor supply decision that might be impacted by health insurance. Another example is the decision to enter the labor market and leave public assistance programs which have health insurance benefits attached to them. As discussed below, most of those who leave welfare programs move to jobs where health insurance is not available. As a result, the decision to move from welfare to work is akin to the decision to move from a job with insurance to one without. As such, "welfare lock" may be another important consequence of the desire to maintain health insurance coverage.

Another important labor supply decision that can be impacted by health insurance is the decision of secondary workers to be employed. In many cases, secondary earners in a family may be the source of health insurance coverage for the family, particularly if the primary earner is self-employed or in a very small firm. As these secondary earners think about leaving their job, perhaps to attend to family matters, they face the same decision as someone switching from a job with health insurance to another one without it, its just that here the alternative is not working at all. But if the family would be happier, health insurance aside, with the secondary worker not working, then there is once again a form of "lock" within the framework developed by the model above.

In the next three sections, we will review what the empirical literature has taught us about the impact of health insurance on labor supply and job mobility. We begin with the outcome that 
appears to have been most impacted by health insurance, namely the retirement of older workers. We then turn to two other groups whose labor supply may also be influenced by health insurance-low income single mothers, and married women and other prime-aged workers. We next address the question of whether health insurance impacts job mobility. We conclude with a discussion of the welfare considerations of these results.

\section{Health Insurance and Retirement}

There is considerable anecdotal evidence that health insurance should be an important determinant of retirement. In a Gallup poll, $63 \%$ of working Americans reported that they "would delay retirement until becoming eligible for Medicare [age 65] if their employers were not going to provide health coverage" despite the fact that $50 \%$ "said they would prefer to retire early-by age 62" (Employee Benefit Research Institute, 1990). Despite these persuasive arguments, and despite the existence of an enormous literature on the effects of health status on retirement decisions, ${ }^{2}$ it is only over the past decade that researchers have focused on the effect of the availability of health insurance coverage on the retirement decision.

As highlighted above, the existence of rents attached to jobs with health insurance implies that workers will be reluctant to move from these jobs to non-employment. We might expect this effect to be strongest for older workers since this group is likely to earn the largest rents from within-workplace pooling of insurance purchase. ${ }^{3}$ This is because of the high and variable medical cost exposure for older individuals, as documented in Table 1, which shows a variety of indicators of health status by age. ${ }^{4}$

There is a clear deterioration in health and an increase in medical utilization/spending after age 55. Compared to those age 35-44, for example, those age 55-64 are: twice as likely to report themselves in fair health and four times as likely to report themselves in poor health; four times as likely to have had a stroke or have cancer, seven times as likely to have had a heart attack, and five times as likely to have heart disease; twice as likely to be admitted to a hospital (with twice as many nights in the hospital if admitted); and 40\% more likely to have a prescribed

\footnotetext{
${ }^{2}$ See, for example, Diamond and Hausman (1984); Bazzoli (1985); Bound (1989); and Stern (1989). See also the recent review in Currie and Madrian (1999).

${ }^{3}$ Unless, of course, employers are able to shift the higher costs of experience rated insurance of older workers to their wages. Sheiner (1999) suggests that this is in fact the case. Even if there is shifting of employer costs to older workers, however, this group may still value employer-provided insurance particularly highly for two reasons. First, the variance of medical expenditures grows with age, increasing the value of having insurance. Second, the differential cost of individual and group policies also grows with age, so that even if older workers are essentially paying for their health insurance through lower wages, they would rather have group coverage than face the individual insurance market.
}

${ }^{4}$ This table summarizes Tables 1-4 in Gruber and Madrian (1996). The medical expenditure statistics in the column labeled " $65+$ " are restricted to those aged 65-74, corresponding to Table 4 in Gruber and Madrian. 
medicine (with twice as many medicines if receiving a prescription). As a result, the medical spending of 55-64 year-olds is almost twice as large, and twice as variable, as that of 35-44 yearolds.

These older workers with depreciating health face an interesting dilemma. On the one hand, their declining health makes retirement more attractive. On the other hand, being in poor health raises the value of employer-provided health insurance, increasing the cost of labor force departure. As already noted, if health insurance loss is costly, the desire to maintain continued health insurance coverage will motivate continued employment over retirement.

Not all individuals, however, lose their health insurance upon retirement. Some employers continue to provide health insurance coverage to their employees following retirement while others do not. Most post-retirement health insurance for early retirees provides equivalent (or near-equivalent) coverage to that of active workers at a similar cost. ${ }^{5}$ For these individuals, health insurance will not be a factor in determining when to retire. Rather, the retirement decision will be determined solely by individual preferences and the financial incentives associated with pensions, social security, and other personal assets.

Eventually, all older individuals will become eligible for Medicare. For those with employer-provided post-retirement health insurance, Medicare should have little impact on retirement. But for those with employer-provided health insurance but without retiree health insurance, Medicare reduces the cost of retirement by replacing the health insurance lost through retirement. ${ }^{6}$ Thus, these individual face an incentive to postpone retirement until they are eligible for Medicare at age 65 .

With this background, what then is the empirical evidence on whether health insurance affects retirement? Table 2 surveys the 16 papers written on this topic. Despite using a variety of estimation techniques and several different types of datasets, almost every examination of the topic has found an economically and statistically significant impact of health insurance on retirement (see the first column of Table 6). We discuss the few notable exceptions in more detail below.

There have been two parallel strands of research on how health insurance affect retirement, one taking a structural approach to modeling retirement behavior, and the other

\footnotetext{
${ }^{5}$ Presumably retirees have already paid for the full cost of post-retirement health insurance through lower wages during their employment years. To our knowledge, the magnitude of this particular wage-health insurance tradeoff has not been empirically estimated.

${ }^{6}$ In fact, Medicare is much less generous than the typical employer-provided health insurance policy. As a result, the majority of Medicare recipients have some type of supplemental ("Medigap") insurance, either through their former employers or purchased in the private market. The private market for this type of insurance is extensively regulated and is not in general plagued by the adverse selection problems typical of the private market for basic nongroup coverage.
} 
looking at reduced form relationships. In both strands of literature, the earliest studies focused on estimating the effect of retiree health insurance on retirement. Subsequent studies have branched out to consider other types of health insurance, such as Medicare, as well.

Several papers have estimated reduced form models of the impact of employer-provided post retirement health insurance on retirement. These papers suggest that retiree health insurance increases the retirement hazard by 30\%-80\% (Gruber and Madrian, 1995; Karoly and Rogowski, 1994; Blau and Gilleskie, 2001a) and reduces the age at retirement by 6 to 24 months (Madrian 1994a; Blau and Gilleskie, 2001a). ${ }^{7}$ In a similar vein, Johnson, Davidoff and Perese (1999) calculate the net present value of the health insurance costs that would be borne if an individual were to retire at a given age, and finds that the higher are these costs, the less likely an individual is to retire.

These reduced form studies that have examined the impact of retiree health insurance on retirement (Madrian, 1994; Karoly and Rogowski, 1994; Headen, Clark and Ghent, 1997; Hurd and McGarry, 1996; Rogowki and Karoly, 2000) all suffer from a similar set of problems-a potential endogeneity between either retiree health insurance availability and the pension incentives associated with retirement, or a correlation between retiree health insurance availability and individual preferences for leisure. Many companies have pension plans that encourage retirement at ages before individuals are eligible for Medicare. These companies, however, are also more likely to offer retiree health insurance benefits. Thus, the pension-related incentives for early retirement are correlated with the health insurance incentives for early retirement. None of these reduced form studies, however, account for the pension-related retirement incentives in any satisfactory manner. If pension-related early retirement incentives are positively correlated with retiree health insurance provision, it is likely that the reduced form estimates of the effect of retiree health insurance on retirement are too large. ${ }^{8}$ Similarly, the selection of individuals with strong preferences for leisure into jobs that offer retiree health insurance will also lead to an upward bias in the reduced form estimates of the effect of retiree health insurance on retirement. ${ }^{9}$

There have been two approaches to dealing with these simultaneity issues. The first is to find variation in insurance availability after retirement that is exogenous to retirement tastes.

\footnotetext{
${ }^{7}$ Blau and Gilleskie (2001a) also find that the magnitudes of the effects of both employer-provided health insurance for active employees and employer-provided health insurance for retirees increase with age.

${ }^{8} \mathrm{We}$ should also note that because of this correlation between pension early-retirement incentives and retiree health insurance availability, the estimated retirement effects of pensions on retirement in the extensive pension literature are also likely to be overstated.

${ }^{9}$ Madrian (1994a) suggests that the extent of the bias generated by selection issues is likely mitigated by the fact that a substantial fraction of younger employees have no idea whether or not their employers offer retiree health insurance. Thus, the availability of retiree health insurance does not appear to be a factor in the employment decisions of many individuals when they accept a job, although it may become a factor in their retirement decisions ex post.
} 
Gruber and Madrian $(1995,1996)$ follow this approach by studying the impact of state and federal "continuation of coverage" laws (e.g. COBRA) which allow individuals to maintain their health insurance from a previous employer for a period of up to 18 months. ${ }^{10}$ This coverage comes at some cost to the former employee, both directly in terms of premium costs, and indirectly as COBRA premiums do not receive the same favorable tax treatment employerprovided health insurance expenditures. COBRA recipients do, however, benefit from the other price-reducing benefits of employer-provided health insurance. COBRA also allows individuals to maintain continuous coverage, a feature that may be important in families who might be denied coverage because of the preexisting conditions exclusions that are part of almost all private market policies and many employer-provided policies as well. The value of identifying the effect of health insurance on retirement from this type of health insurance coverage is that in contrast to post-retirement health insurance, it is completely independent of omitted personal characteristics that may be correlated with both post-retirement health insurance and the incentives to retire, and it is completely independent of omitted job characteristics, such as pension plan provisions, that may be correlated with both employer-provided and retiree health insurance. Thus, it provides a relatively clean source of variation for identifying the effect of health insurance on retirement.

Gruber and Madrian (1995) find that continuation coverage increases the retirement hazard by $30 \%$. While this is at the lower end of the estimated magnitudes for the impact of retiree health insurance coverage on retirement, this is a very large effect given that COBRA provides only 18 months of coverage for which individuals must pay the full average group cost. Thus, these findings use a relatively exogenous source of variation to confirm that retirement is very sensitive to health insurance availability.

Berger, et al. (2000) also examine the impact of COBRA on the joint employment/retirement decisions of husbands and wives in married couple families. In contrast to Gruber and Madrian, however, they identify the impact of COBRA from variation in firm size: firms employing fewer than 25 individuals are exempt from the federal law requiring continuation coverage. They find little impact of COBRA on retirement using this approach, but their approach is not a particularly compelling one. First, firm size is likely to be correlated with other factors that influence retirement such as the availability and/or generosity of pension coverage, and the direction of the effect of these omitted variables on retirement behavior is not unambiguous. Second, the impact of COBRA in their empirical specification is identified from an interaction between health insurance coverage and firm size in a sample that is relatively small

\footnotetext{
${ }^{10}$ Continuation of coverage laws mandate that employers must allow employees and their dependents the option to continue purchasing health insurance through the employer's health plan for a specified period of time after coverage would otherwise terminate (the reasons that health insurance might terminate include things such as a job change, a reduction in hours, or an event which would cause a dependent to lose coverage such as a divorce). Minnesota, in 1974, was the first state to pass a continuation of coverage law. Several states passed similar laws over the next decade. The federal government mandated this coverage at the national level in 1986 with a law now commonly referred to as COBRA. See Gruber and Madrian $(1995,1996)$ for more detail on continuation of coverage laws.
} 
to begin with, so the statistical precision of the resulting estimates are likely to be low no matter what the true effect is.

The second approach to dealing with the potential endogeneity between health insurance availability after retirement and other incentives to retire is to develop a richer structural model of retirement decisions. Gustman and Steinmeier (1994) were the first paper to follow this approach. They use RHS data to estimate a structural model that incoporates both pension and health insurance related incentives to retire. They estimate that retiree health insurance reduces the age at retirement by a mere 1.3 months and decreases the labor force participation rate at age 62 by only 1 percentage point. However, they also find that retiree health insurance increases the retirement hazard at age 62 by 6 percentage points (47\%). These seemingly disparate results arise because the nature of the structural model estimated by Gustman and Steinmeier relies on an assumption about the rate at which retiree health insurance benefits accrue (analogous to a pension accrual rate). Their paper assumes that eligibility for retiree health insurance coincides with the eligibility for pension early retirement benefits. ${ }^{11}$ These assumptions about retiree health insurance eligibility imply that as with pensions, individuals who have not yet "vested" in their retiree health insurance benefits will delay retirement until they are eligible for these benefits, but once eligible, there will be a large increase in the retirement hazard. A model making different assumptions about the eligibilty for retiree health insurance could yield very different estimates. Note, however, that even within the context of the assumptions made by Gustman and Steinmeier (1994), retiree health insurance has a strong influence on the timing on retirement even if its estimated effects on overall labor force participation are not large.

A more recent, and highly sophisticated structural dynamic programming model of retirement using RHS data is estimated by Rust and Phelan (1997). This complicated model is computationally demanding, but potentially can provide a richer framework for capturing the dynamics of the retirement decision. Even after accounting for the social security incentives associated with retirement, Rust and Phelan estimate sizeable affects of health insurance on retirement. For example, they find that retiree health insurance decreases the probability of working full-time by 10 percentage points $(12 \%)$ at ages $58-59$, by 20 percentage points at ages $60-61(29 \%)$, and by 16 percentage points $(25 \%)$ at ages $62-63$. The major obstacle to generalizing from the results of this study is that the sample was restricted to men without a pension, a somewhat non-representative sample. While it is difficult to compare these estimates of the effects of retiree health insurance on labor force participation with the effects on the retirement hazard estimated in most of the reduced form papers, both sets of results suggest a rather large effect of health insurance on retirement.

Two recent working papers using structural models and more-recent HRS data estimate smaller effects of retiree health insurance on retirement behavior. The first, by Blau and Gilleskie (2001b), uses the first two waves of the HRS to estimate a joint model of retirement for

\footnotetext{
${ }^{11}$ Note that employee benefit data from the BLS suggests that retiree health insurance eligibility is only contingent on pension eligibility for $25 \%$ of those working in firms that provide retiree health insurance.
} 
husbands and wives. They find little impact of health insurance on individual or joint retirement behavior when the effect of health insurance is forced to operate solely through the budget constraint in the model. When they allow the utility function to be directly impacted by health insurance availability, they find that retiree health insurance availability does lead to earlier retirement, although they hesitate to place an economic interpretation on these results. The authors do not speculate about what could drive the discrepancy between the results of the purely structural model versus allowing for utility directly from having health insurance: does the availability of retiree health insurance proxy for some other factor, perhaps a preference parameter, for early retirement? Or do individuals value health insurance coverage too highly? Or does the model miss some important costs potentially associated with being uninsured? While these results suggest that health insurance may not be as important a factor in retirement decisions as previous research has suggested, there are some important caveats in the interpretation of these results. First, because of data issues, the sample used in the estimation has a much lower rate of health insurance coverage than a representative sample of HRS respondents. To the extent this skews the sample toward being comprised of people whose actions are less likely to be responsive to the availability of health insurance, the simulated effects of health insurance on retirement may be understated. Second, the age of the sample, those 51-63 in the first wave of the HRS, is relatively young for a study in which retirement decisions are only actually observed over the next two years. To the extent that Medicare eligibility motivates retirement at age 65, its effects are not actually observed in the data even though the value of Medicare is modeled in the estimation.

The second paper estimating a structural model of retirement using HRS data is by French and Jones (2001). They also suggests that health insurance has little impact on retirement behavior. French and Jones posit that individuals with high levels of wealth should be less sensitive to the availability of health insurance in their retirement decisions because they can afford to self-insure. They find little difference, however, in the retirement hazards of individuals with retiree health insurance depending on the level of assets held by these individuals. Their study, however, does not adequately account for other underlying differences across individuals that affect both asset levels and retirement. For example, individuals in professional occupations (doctors, lawyers), have high levels of assets, jobs that are likely to allow for gradual transitions from full-time work to retirement, and jobs that are less likely to be impacted by health declines that accompany aging. Thus, the nature of the jobs held by high asset individuals implies that they are likely to have very different retirement hazards than individuals with low levels of assets, even if their valuation of retiree health insurance is the same. Overall, the approach taken to identifying the affect of health insurance on retirement in this paper does not seem well-grounded.

Evidence on the relationship between Medicare eligibility and retirement is much more limited. Identification of the effect of Medicare is complicated by the fact that Medicare eligibility coincides with the social security normal retirement age. In their structural dynamic programming model, Rust and Phelan (1997) identify the effect of Medicare from the expected distribution of medical care expenditures and a risk aversion parameter included in the dynamic program. They find that men with employer-provided health insurance but without employer- 
provided retiree health insurance are indeed less likely to leave the labor force before age 65 than men whose health insurance continues into retirement. Somewhat paradoxically they find that even after age 65, men with employer-provided health insurance but without employer-provided retiree health insurance have a lower retirement hazard. They suggest that this may be due to the fact that Medicare coverage is much less generous than the "cadillac" health insurance coverage provided by employers. One reason for this, posited by Madrian and Beaulieu (1998), is that employer-provided health insurance typically covers dependents while Medicare does not. Consequently, a labor force departure for an individual with employer-provided health insurance but not post-retirement health insurance will result in a loss of health insurance coverage for both one's self and one's spouse. The lack of Medicare dependent coverage creates an incentive for men with employer-provided health insurance who are themselves Medicare eligible to continue working until their wives reach age 65 and are Medicare eligible as well. ${ }^{12}$ Madrian and Beaulieau show that at all ages, the retirement hazard for 55-69 year-old married men increases substantially when their wives reach age 65 and are eligible for Medicare, suggestive evidence of yet another link between health insurance and retirement. The results of Madrian and Beaulieu, however, are suggestive at best as the data used in their analysis-1980 and 1990 Census data-contains no information on either pensions or health insurance.

In contrast to Rust and Phelan (1997) and Madrian and Beaulieu (1998), Lumsdaine, Stock and Wise (1994) find little effect of Medicare on retirement decisions. In their paper, they incorporate the value of Medicare into a structural retirement model estimated using the personnel records from a large U.S. firm. The company analyzed, however, provided retiree health insurance to its employees, and thus for these employees there was little additional value associated with Medicare. In this context, the lack on an effect is unsurprising, and one would certainly be hesitant to generalize from these conclusions.

Despite the overall consensus of the evidence that there is an effect of health insurance on retirement, there is still quite a lot of research to be done in quantifying the magnitude of this effect. This is due in large part to data constraints that limit the reliability or the generality of the results in the current literature. ${ }^{13}$ The next step to be taken in this literature is to estimate the effects of health insurance on retirement while more fully accounting for the age-specific retirement incentives associated with both Social Security and pensions using current data. For several years now, researchers have been pinning their hopes on the HRS for providing the "ultimate answer" to the question of how health insurance affects retirement because it contains information with which to do this. With now almost a decade having passed since the first

\footnotetext{
${ }^{12}$ Wives are, on average, three years younger than their husbands (Madrian and Beaulieu, 1998).

${ }^{13}$ Data limitations include the lack of information on pension plan availability (Gruber and Madrian, 1995 and 1996; Madrian, 1994a; Karoly and Rogowski, 1994) or lack of information on specific pension plan incentives (Rogowski and Karoly, 2000; Blau and Gilleskie, 2001a; French and Jones 2001); the lack or quality of measures of employer-provided or retiree health insurance (Madrian, 1994a; Karoly and Rogowski, 1994; Rust and Phelan, 1997; Gustman and Steinmeier, 1994); the restrictiveness of the sample (Rust and Phelan, 1997; Lumsdaine, Stock and Wise, 1994); and the age of the data (Rust and Phelan, 1997 and Gustman and Steinmeier, 1994).
} 
fielding of the HRS, the literature has been slow to progress on this front. While several papers have examined the effect of health insurance on retirement in the HRS, only one to date has used data beyond Wave II. ${ }^{14}$ But incorporating the later waves is clearly critical, as none of the ageeligible HRS respondents have reached 65 in Wave II. Our hopes for the "ultimate answer" from the HRS are somewhat tempered by issues of sample size. After restricting their sample to ageeligible couples with valid data from both the Social Security and HIPPS supplements, Blau and Gilleskie (2001b) are left with a sample of less than 700 couples. This strikes us as a rather small sample to work with, and one likely to result in imprecise estimates for many variables of interest. Adding in single individuals and/or non-age-eligible individuals would increase the sample size, but depending on the context, one may or may not wish to do this.

Beyond the issue of estimating an integrated economic analysis of the effects of Social security, pensions, health insurance, and health on retirement, several other refinements of the literature are also warranted. Recent research on retirement has recognized that for many individuals, retirement is not the "absorbing state" that simplified theories portray it to be. A nontrivial fraction of workers move from full-time employment to part-time employment and then to complete retirement. ${ }^{15}$ Many other older workers make several transitions in and out of the labor force before making the final "absorbing" switch to retirement. And a sizeable fraction of non-retired workers state a preference for a gradual transition from work to retirement (Hurd and McGarry, 1996). Health insurance, however, may be an important factor limiting the ability of workers to "retire" as they wish. Because health insurance is usually attached to full-time rather than to part-time work, it may be difficult for workers to gradually transition to part-time work if doing so involves relinquishing health insurance. Rust and Phelan (1997) estimate that men with employer-provided retiree or other non-employment based health insurance are much less likely to be working full-time than men whose employers provide health insurance but not retiree health insurance, but they are much more likely to be working part-time. This suggests that health insurance may indeed be an important factor determining whether older workers are able to make a gradual transition from work to retirement as desired.

Consistent with most of the retirement literature, the literature on health insurance and retirement has focused almost exclusively on men. ${ }^{16}$ This is because the labor force participation rate of older women has historically been low, and among older women who do work, a sizeable fraction are in fact insured by their husbands. Consequently, it has been assumed that the potential behavioral impact among women is small. As the labor force participation rate of older women increases, however, and as an increasing number of older women become the sole head of household or the primary insurers of their families, the question of whether health insurance impacts women differentially than men warrants further investigation.

\footnotetext{
${ }^{14}$ French and Jones (2001) use data from Waves I through IV.

${ }^{15}$ See Ruhm (1990) and Peracchi and Welch (1994) for a more complete discussion of "bridge jobs" to retirement.

${ }^{16}$ Lumsdaine, Stock and Wise (1994), Headen, Clark and Ghent (1997), Hurd and McGarry (1996), Blau and Gilleskie (2001b), Johnson, Davidoff and Perese (1999) and Berger et al. (2000) are the notable exceptions.
} 


\section{Health Insurance and the Labor Supply of Lower Income Single Mothers}

Another margin along which health insurance might affect labor market outcomes is through the labor supply decisions of potential public assistance recipients. Table 3 describes the 16 papers that we survey on this topic, and the results of these surveys are summarized in the second column of Table 6. A key feature of both the Temporary Assistance for Needy Families (TANF, formerly Aid to Families with Dependent Children or AFDC) and the Supplemental Security Insurance (SSI) programs is that, in addition to cash and other benefits, recipients qualify for Medicaid. Because the groups who qualify for these types of programs-low income single female-headed families and the low income disabled and elderly-tend to qualify for lowwage, low-skilled jobs without health insurance, the coupling of Medicaid with public assistance encourages individuals to sign up for and to remain enrolled in public assistance programs. The budget set for these individuals is shown by budget constraint MABC in Figure 1. The nonlinearity in the budget set generated by the loss of Medicaid (segment AB) creates an incentive to reduce labor supply from $\mathrm{H}$ to $\mathrm{H}^{\prime}$.

Because Medicaid participation has historically been colinear with public assistance participation, the "Medicaid effect" on labor supply has been difficult to distinguish from the "Welfare effect." 17 Four identification strategies have been pursued. The first exploits variation in the demand for health insurance coverage generated by differences in expected medical expenditures. Ellwood and Adams (1990) follow this approach using administrative Medicaid claims data, while Moffit and Wolfe (1992) do so with the SIPP. Both papers find that the probability of exiting public assistance decreases substantially as the imputed value of Medicaid rises. Moffitt and Wolfe also show that the value of maintaining Medicaid coverage has a significant negative impact on the labor force participation of single mothers.

Although these results support the notion that individual labor supply decisions are made in such a way as to maintain health insurance coverage, this identification strategy is vulnerable because the primary determinant of differences in the valuation of Medicaid benefits-namely differences in health status-is likely to have a strong independent effect on both labor supply and welfare participation. ${ }^{18}$ Both studies recognize this criticism and attempt to address it by examining the effects of the family head's health status separate from that of the children in the family. Ellwood and Adams (1990) find similar effects for expected expenditure increases generated by either the family head's health status or the health status of children. In contrast, Moffitt and Wolfe (1992) find that expected expenditure increases that are generated by the health status of the children lead to labor supply effects that are one-third as large as those generated by expenditure increases of the family head. However, Wolfe and Hill (1995) show that having a disabled child leads to a reduction in maternal labor supply, so even this approach

\footnotetext{
${ }^{17}$ This also suggests that estimates of the effect of AFDC on labor supply that do not recognize the colinearity of AFDC and Medicaid may overstate the effects of AFDC.

${ }^{18}$ See Currie and Madrian (1999) for a survey of the extensive literature on health and labor supply.
} 
to disentangling the effect of expected medical expenditures on labor supply as separate from the effect of health is problematic.

A second approach taken has been to use variation in the generosity of the state Medicaid programs to identify the value of Medicaid to potential welfare recipients. The generosity of the state Medicaid programs is typically specified as some measure of per capita Medicaid spending in the state (e.g., spending per recipient, or average spending for a family of a given size). This general approach has been pursued by Blank (1989), Winkler (1991) and Montgomery and Navin (2000). Blank finds no effect of Medicaid expenditures on either AFDC participation or labor supply. Winkler (1991) and Montgomery and Navin (2000) both find small effects of Medicaid expenditures on labor force participation, although the effects in Montgomery and Navin disappear once state fixed effects are included as regressors.

Using average state Medicaid expenditures as a proxy for the value of Medicaid to potential recipients is problematic for two reasons. First, this measure is likely to be a very noisy measure of the underlying value of Medicaid to potential recipients. This is because variation in average expenditures is likely to reflect not only variation in the generosity of the insurance, but also variation in the underlying health of those covered and variation in the utilization patterns of patients and practice patterns of physicians. This type of measurement error will result in attenuation bias, making it less likely to find an effect of Medicaid on labor market outcomes if such an effect exists. Second, the variation in state Medicaid expenditures that is driven by the underlying health of the Medicaid population is likely to be spuriously correlated with labor force participation decisions. Because health is a significant determinant of labor force participation, states with relatively healthy populations are likely to have both high labor force participation rates and low average Medicaid expenditures. This spurious correlation between labor force participation and average Medicaid expenditures will also bias one against finding a relationship between the value of Medicaid and labor force outcomes.

More recent papers have attempted to exploit the fact that a series of legislative initiatives in the late 1980s severed the link between Medicaid and welfare participation for various groups of mothers and children. These initiatives allowed women to maintain their Medicaid coverage for a pre-specified period of time after leaving welfare, and extended Medicaid coverage to many groups of low-income children indefinitely (in terms of Figure 1, these initiatives change the budget constraint from MABC to MD). Currie and Gruber (1996a, b) estimate that as a result of these expansions, almost one-third of children and one-half of pregnant women are eligible for Medicaid coverage of their medical expenses.

Yelowitz (1995) was the first to exploit these Medcaid expansions as a way to identify the effect of Medicaid coverage on AFDC and labor force participation. He finds evidence that these expansions in Medicaid availability led to a small but statistically significant increase in the labor force participation rate of single mothers. Meyer and Rosenbaum (2000b) contest these results, however, claiming that the effects estimated by Yelowitz are a result of miscalculating the AFDC income threshold and forcing the effect of the AFDC and Medicaid income eligibility thresholds to have the same effect. Once Meyer and Rosenbaum (2000b) correct the calculation of the 
AFDC income threshold the allow for different coefficients on the AFDC and Medicaid income thresholds, they find that the labor force participation effects estimated in Yelowitz (1995) are driven entirely by AFDC and not by the Medicaid expansions. ${ }^{19}$ In an unpublished note, Yelowitz (1998c) claims that his findings remain relatively robust to the income calculation thresholds. But, regardless of whether the effects exist or not, even the largest estimates here suggest that they are small.

Yazici (1997) also finds little effect of the Medicaid expansions on labor force participation, although her NLSY sample is so small that it is unlikely that she would be able to obtain statistically significant estimates of any effect unless it were a particularly large one. In one of the few studies on the labor supply of single mothers using longitudinal data, Ham and Shore-Sheppard (2000) also examine the effect of the Medicaid expansions and find that they shorten both non-employment and welfare spells, with stronger effects for the long-term nonemployed and long-term welfare recipients. Their effects largely go away when year effects are included in the regressions, although year effects remove a substantial fraction of the variation in the Medicaid expansions with which to identify the effect of Medicaid.

Decker (1993) pursues a related identification strategy by examining the effect of the introduction of the Medicaid program in the late 1960s and early 1970s on state AFDC participation. Because the Medicaid program was phased in across the states over a period of several years, this provides a credible source of identification. Using both state-level data on AFDC caseloads and individual (CPS) data on AFDC participation, she estimates a significant and sizeable $21 \%$ increase in the likelihood of AFDC participation. Her estimates on the effects of labor force participation, however, are insignificant, and suggest that the increase in AFDC participation is due primarily to increased take-up among those already eligible and not to reductions in labor supply leading to increased eligibility.

A final identification strategy has been to exploit differences in the availability or generosity of employer-provided health insurance that welfare recipients could potentially obtain were they to become employed. This approach is pursued by Perreira (1999) using administrative data on Medicaid participation in California, and by Meyer and Rosenbaum (2000b) using the CPS. Perraira finds that a 2.5 percentage point $(5 \%)$ increase in the countrywide availability of employer-provided health insurance decreases the median Medicaid spell length by 3-11 months (10-37\%). Meyer and Rosenbaum (2000b), on the other hand, obtain somewhat contradictory results. They find that higher contribution rates for employer-provided health insurance lead to a decrease in the employment of single mothers, consistent with a story that as employer-provided health insurance becomes more expensive, Medicaid becomes relatively more valuable. But they also find that an increase in the value of employer-provided health insurance decreases the employment of single mothers. Meyer and Rosembaum (2000b)

\footnotetext{
${ }^{19}$ See Meyer and Rosenbaum (2001) and Meyer and Rosenbaum (2000a) for additional evidence suggesting that the Medicaid expansions had little impact on the labor supply increases of single mothers over the past 15 years.
} 
posit a demand-side argument for this latter affect-that when employers are more likely to offer employer-provided health insurance, they take steps to reduce employment.

In practice, using variation in the availability of employer-provided health insurance to identify the effect of health insurance on the labor supply of single mothers is a tricky proposition at best. Health insurance coverage rates vary quite significantly geographically, by income, and by hours worked. Given this heterogeneity, any measure of "health insurance availability" or "health insurance value" for single mothers is likely to be quite arbitrary. Consequently, any variation in these measures is likely to be dominated by measurement error and the results are quite likely to be subject to a significant degree of attenuation bias.

A series of other studies by Yelowitz have also examined the effect of Medicaid on public assistance participation other than through the TANF or AFDC programs. Although these studies do not examine labor supply outcomes directly, they all find that the coupling of Medicaid with other types of public assitance programs increases the participation in public assistance programs. ${ }^{20}$

Overall, the literature suggests that health insurance availability, and Medicaid in particular, has either no or a very small effect on the labor force participation of low income single mothers. This is somewhat surprising given the potential importance of health insurance for this population and their children. On the other hand, there is some evidence that the decision to participate in welfare programs, conditional on labor supply decisions, is fairly responsive to the availability of health insurance.

But the last word has clearly not been written on this topic. Given the remaining controversy over whether the Medicaid expansions reduced welfare participation and increased labor supply, there is room for more work on refining these effects. And the significant new expansions in public insurance eligibility for children through the CHIP, along with changes in state welfare programs resulting from welfare reform, provide further variation that can be exploited to assess the impact of public insurance on the labor supply and welfare participation decisions of single mothers.

\section{Health Insurance and the Labor Supply of Married Couples}

Married women, and to a lesser extent married men, are another group whose labor force participation is likely to be impacted by the availability of health insurance coverage. And, although most of the interest in the effect of health insurance on labor force participation in both policy and academic circles has been focused on older workers and welfare recipients, the potential impact in terms of aggregate effects on total hours worked may very well be largest for

\footnotetext{
${ }^{20}$ See Yelowitz (2000) for evidence on elderly SSI recipients; Yelowitz (1998a and 1998b) for evidence on disabled SSI recipients; and Yelowitz (1996) for evidence on Food Stamp receipt.
} 
prime-aged workers, particularly married women who are typically estimated to have a large labor supply elasticity. Given the responsiveness or married women to wage changes, one might expect a sensitivity to the availability of health insurance coverage as well.

There have been 7 papers examining the labor supply of prime-aged workers who are not single mothers. These are described in Table 4 with the results summarized in the third column of Table 6. In most of these papers, the identification of the effect of health insurance on labor supply comes from comparing the labor force participation and hours worked of married women whose husbands have employer-provided health insurance with the labor force participation and hours worked of married women whose husbands do not. This identification strategy rests on the assumption that a husband's employer-provided health insurance is exogenous. ${ }^{21}$ This assumption is clearly problematic if husbands and wives make joint labor supply and job choice decisions. Putting this caution aside, all four studies looking at the labor force participation of married women using U.S. data find strong evidence that the employment and hours decisions of married women do in fact depend on whether or not health insurance is available through a spouse's employment. Buchmueller and Valletta (1999) estimate that the availability of spousal health insurance reduces the labor force participation of married women by 6-12\%; Olson (1998) estimates a similar 7-8\% reduction in labor force participation; Schone and Vistnes (2000) estimate a 10 percentage point reduction in labor force participation; while Wellington and Cobb-Clark (2000) estimate a substantial 20 percentage point reduction in labor force participation.

This research also suggests that health insurance impacts not only the decision of whether or not to work, but also job choice decisions for women who do work. Using a multinomial logit to categorize employment outcomes (full-time jobs with health insurance, full-time jobs without health insurance, part-time jobs with health insurance, part-time jobs without health insurance, and non-employment), Buchmueller and Valletta (1999) also estimate that spousal health insurance reduces the probability of working in a full-time job with health insurance by 8.5 to 12.8 percentage points, increases the probability of working in a full-time job without health insurance by 4.4 to 7.8 percentage points, and increases the probability of working in a part-time job by 2.8 to 3.3 percentage points. Schone and Vistnes (2000) estimate a reduction in full-time work of 14 percentage points, an increase in part-time work of 2 percentage points, and a decrease in the likelihood of having a job with employer-provided health insurance of 15 percentage points. Wellington and Cobb-Clark (2000) estimate an annual hours reduction of 8$17 \%$ for married women. Finally, using an interesting application of semi-parametric estimation techniques, Olson estimates an average decline in weekly hours of $20 \%$ (5 hours per week) for married women whose husbands have health insurance.

\footnotetext{
${ }^{21}$ Schone and Vistnes (2000) attempt to address the potential endogeneity of spousal health insurance coverage by instrumenting for its availability with characteristics of the husband's job (e.g. firm size, industry and occupation). To the extent that husbands seek out jobs with health insurance, however, the job characteristics that make employers more likely to offer health insurance are simply the mechanism through which the health insurance endogeneity operates.
} 
A problem with all of the above-described studies on health insurance and the labor supply of married women is that the a husbands' employer-provided health insurance coverage could be endogenous to the labor force participation decisions of their wives. There is at least some evidence, however, that these results are driven by the availability of health insurance per se, and not by its correlation with any underlying taste for market work of wives. First, Buchmueller and Valletta (1999) find that the effect of husbands' health insurance on wives' labor supply is strongest in larger families, which is consistent with the notion that it is the value of health insurance that is driving the results and not simply tastes for market work. Second, Buchmueller and Valletta (1999) find that wives employed in jobs without health insurance work longer, rather than shorter hours, if their husbands have health insurance. In addition, Olson (1998) shows that conditional on working at least 40 hours per week, wives have a very similar distribution of hours regardless of whether or not their husbands have health insurance. Finally, both Buchmueller and Valletta (1999) and Olson (1998) find that husband's health insurance reduces the probability of full-time employment for their wives quite substantially, but has only small effects on the probability of part-time employment. These findings taken together provide support for a causal explanation for the effect of husbands health insurance on the labor force participation of their wives, rather than a story based on unobserved correlations with tastes for market work.

In one of the few studies of health insurance and the labor market using non-U.S. data, Chou and Staiger (2001) examine the effects of health insurance on spousal labor supply in Taiwan. Before March, 1995 when Taiwan implemented a new National Health Insurance program, health insurance was provided primarily through one of three government-sponsored health plans which covered workers in different sectors of the economy. Historically these plans covered only workers and not their dependents. Thus, own employment was the only way for most individuals to obtain health insurance. There was one exception-coverage for spouses was extended to government workers in 1982, and subsequently to children and parents as well. By exploiting this variation in the availability of dependent health insurance coverage, Chou and Staiger (2001) are able to identify the effect of health insurance on employment. They estimate that the labor force participation rate of women married to government employees declined by about $3 \%$ after they were able to obtain coverage as spousal dependents relative to the labor force participation rate of women married to other private-sector workers. They estimate similar declines in labor force participation for the wives of private-sector workers following the 1995 implementation of National Health Insurance which made health insurance available to all individuals. Their results are largely corroborated in an analogous study by Chou and Lui (2000) using a different dataset on labor force participation in Taiwan.

Only two studies have empirically examined the effect of health insurance on the labor force participation decisions of prime-aged men. The first, by Wellington and Cobb-Clark (2000), examines the effect of spousal health insurance on the employment decisions of both husbands and wives. As noted earlier, they find large effects of husbands' health insurance on the labor force participation of married women. They also find an effect of spousal health insurance on the labor force participation of married men: having a wife with health insurance reduces husbands' labor force participation by $4-9$ percentage points and annual hours by $0-4 \%$. 
In the only other study of health insurance and employment among prime-age men, Gruber and Madrian (1997) exploit the continuation of coverage mandates discussed earlier in the context of retirement to consider the impact of health insurance on the transition from employment to non-employment and on the subsequent duration of non-employment. They find that mandated continuation coverage increases the likelihood of experiencing a spell of nonemployment by about $15 \%$. It also increases the total amount of time spent non-employed by about 15\%. Although Gruber and Madrian (1997) note that the availability of health insurance while without a job might be expected to increase the duration of non-employment spells, they are unable to test this proposition because the effect of health insurance on transitions from employment to non-employment implies the possibility of a composition effect in the group of individuals who are non-employed. This issue is, however, clearly one of interest, and warrants further research.

Overall, the body of empirical literature on the effects of health insurance on the labor supply of married women and other prime-aged workers gives strong and consistent support to the notion that health insurance affects individual labor supply decisions. When there is a ready source of health insurance available not attached to one's own employment, individuals (particularly married women) are much less likely to be employed. This suggests that the institutional link between health insurance and employment may be a significant factor in the employment decisions of individuals. But this literature is somewhat limited by a lack of identification strategies that are as convincing as those used in the literatures on retirement, welfare participation, and (as discussed next) job mobility.

\section{Health Insurance and Job Turnover}

The most-studied labor market outcome in the health insurance and labor markets literature has been that of job choice. The 18 papers we survey on this topic are described in Table 5, and the results from these studies are summarized in the final column of Table 6. Recognizing that own employer-provided health insurance is likely to be correlated with other potentially unobserved job attributes that also affect job turnover decisions, only a handful of studies have looked directly at the impact of own employer-provided health insurance on job mobility. The first (Mitchell, 1982) makes no claim of trying to "identify" the effect of health insurance on job choice in this fashion. Two others, (Buchmueller and Valletta, 1996; Gilleskie and Lutz, forthcoming) attempt to use other controls to account for the positive correlation between health insurance and other job amenities that are also likely to reduce job turnover (the Buchmueller and Valletta study employs both this identification strategy and that discussed below). The last (Dey, 2000) estimates a highly structural model of job choice.

The identification strategy pursued in almost all of the other analyses of job turnover has been to compare the probability of job departure or turnover of otherwise observationally equivalent employees who differ only in the value that they are likely to place on a current employer's health insurance policy. Various measures of the value of health insurance have been used. These include: 
- Health insurance coverage from a source other than one's current employer, most often through a spouse or some sort of continuation coverage such as COBRA (Cooper and Monheit, 1993; Madrian, 1994b; Gruber and Madrian, 1994; HoltzEakin, 1994; Penrod, 1994; Buchmueller and Valletta, 1996; Holtz-Eakin, Penrod and Rosen, 1996; Anderson, 1997; Kapur, 1998; Slade, 1997; Madrian and Lefgren, 1998; Berger, Black and Scott, 2001; Gilleskie and Lutz, forthcoming; Spaulding, 1997).

- $\quad$ Family size (Madrian, 1994; Kapur, 1998; Berger, Black and Scott, 2001)

- $\quad$ Health conditions (Cooper and Monheit, 1993; Madrian, 1994b; Penrod, 1994; Holtz-Eakin, Penrod and Rosen, 1996; Anderson, 1997; Kapur, 1998; Brunetti, et al., 2000; Stroupe, Kinney and Kniesner, 2000; Berger, Black and Scott, 2001; )

- $\quad$ Health status (Holtz-Eakin, 1994; Penrod, 1994; Anderson, 1997; Slade, 1997; Brunetti, et al., 2000; Berger, Black and Scott, 2001)

From the policy standpoint of evaluating the likely effect on job turnover of having health insurance that does not depend on one's own employment, identification based on the availability of non-own-employment based sources of health insurance seems most appealing, if such alternative sources of health insurance coverage are in fact exogenous. The criticism of using this type of identification, of course, is that the presence of alternative, non-employment based sources of health insurance may not be exogenous. By far the most prevalent source of such coverage is the employment-based health insurance available to one's spouse, and to the extent that couples make joint family employment and health insurance coverage decisions, the health insurance available through one spouse could impact the employment and job choice decisions of the other spouse. Madrian (1994b) first used the availability of spousal health insurance as a means to identify job-lock, and estimated that it increased turnover by $25 \%$. Others who have followed the same strategy have obtained qualitatively similar results (Buchmueller and Valletta, 1996; Berger, Black and Scott, 2000). In their study of job turnover, Buchmeuller and Valletta (1996) try to account for the potential endogeneity of spousal health insurance and find little impact on their estimated coefficients from doing so. This suggests that even though spousal health insurance may be jointly determined by husbands and wives, from the standpoint of looking at job turnover it can perhaps be treated as being exogenous. This conclusion is also echoed in the papers by Buchmueller and Valletta (1999) and Olson (1998) on spousal health insurance and the labor supply of married women discussed in Section V above.

Holtz-Eakin (1994) follows a similar strategy and fails to find a significant impact of spousal health insurance on job turnover. However, his results are difficult to evaluate because of well-documented problems associated with the turnover variables in the data used in his analysis (the PSID). Because the PSID does not do a good job tracking job changes, how exactly one defines a job change can result in very different job turnover rates, something that suggests the possibility of measurement error, no matter which definition is chosen. With classical measurement error and a continuous dependent variable, such measurement error will simply 
result in a loss of efficiency (bigger standard errors). In the context of limited dependent variable models, however, measurement error in the dependent variable can lead to biased and inconsistent coefficient estimates. Hausman, Scott Morton and Abrevaya (1998) show how this occurs in a general context. Brown and Light (1992) show that in the specific context of job choice in the PSID, how the dependent variable is defined is critical, and varying definitions can actually result in statistically significant estimated coefficients that are of opposite signs! These results lead us to question the appropriateness of the PSID as a data source with which to investigate job turnover. ${ }^{22}$

Measurement error in the dependent variable is also likely to be quite important in the one study that uses the CPS. Because the CPS does not ask questions about job change, Brunetti et al. (2000) use industry and occupation changes as a measure of job change in the CPS. Industry and occupation can change, however, even without a change of employer, and the significant variation in their measure of "job change" depending on how this variable is defined (change in industry, change in occupation, or change in both) certainly suggests that these variables are very likely to contain a substantial degree of measurement error.

Kapur (1998) criticizes the approach used in Madrian (1994b) and Buchmueller and Valletta (1996) not because of the potential endogeneity of spousal health insurance, but because the identification of job-lock rests on a comparison of mobility difference across those who do and do not have health insurance. She claims that substantial differences in the characteristics of individuals employed in jobs with health insurance relative to individuals employed in jobs without health insurance invalidates making such a comparison.

It is true that there are substantial differences between individuals with and without their own employer-provided health insurance (see Table 1 of Kapur, 1998). In using spousal health insurance to identify job-lock, however, Madrian (1994b) obtained extremely similar estimates whether she used a difference-in-difference estimate based on men with and without their own health insurance, or whether she looked only at the direct effect of spousal health insurance on men with employer-provided health insurance. Thus, using a difference-in-difference approach with a heterogeneous sample or looking at a simple difference in the more homogeneous sample advocated by Kapur (1998) gives very similar estimates.

Kapur (1998) suggests an alternative approach for identifying the effects of health insurance on job mobility: restrict the sample to individuals with employer-provided health insurance and examine the differential effect of health conditions or health status on those with and without spousal health insurance. The notion here is that lacking an alternative source of health insurance should be a greater impediment to mobility for those with family health conditions. Trying to identify the effect of health insurance on job turnover using variation across individuals in health conditions has been pursued by a number of researchers, including

\footnotetext{
${ }^{22}$ Holtz-Eakin (1994), Holtz-Eakin, Penrod and Rosen (1996), and Spaulding (1997) all use PSID data to examine the impact of health insurance on job mobility.
} 
Kapur (1998), Monheit and Cooper (1993), Penrod (1994), Holtz-Eakin (1994), Holtz-Eakin, Penrod and Rosen (1996), Brunetti et al. (2000), Stroupe, Kinney and Kniesner (2000), and Berger, Black and Scott (2001). The precise identification strategies pursued have varied somewhat across these papers, but the basic approach is one of the following:

1) Include all individuals with and without employer-provided health insurance in the sample and identify job-lock off of an interaction between employer-provided health insurance and some measure of health conditions;

2) Include only individuals with employer-provided health insurance in the sample and identify job-lock off of an interaction between the availability of health insurance through a spouse and some measure of health conditions;

3) Include all individuals with and without employer-provided health insurance in the sample and use a difference-in-difference-in-difference approach to identify job-lock off of a three-way interaction between own health insurance, spouse health insurance and some measure of health conditions.

With the exception of Stroupe, Kinney and Kniesner (2000), none of the papers in this genre have found any statistically significant effect, positive or negative, of job-lock. Although the approach suggested above has intuitive appeal, its actual implementation is somewhat problematic. First, the actual prevalence of severe health problems and/or extensive medical care utilization in the prime-aged working population is low. This will, in general, lead to reduced precision in the estimates. This general issue of power is further compounded in difference-indifference or difference-in-difference-in-difference identification strategies, in which the identification rests on the interaction between health status or medical care utilization and some measure of health insurance coverage. The prevalence of the joint state of health problems and spousal health insurance, or of health problems, own insurance and spousal health insurance, is even lower. Thus, the ex ante likelihood of being able to estimate statistically significant effects is small. Stroupe, Kinney and Kniesner (2000) overcome the low prevalance problem associated with chronic illnesses by using data which vastly oversamples individuals who themselves or whose family members have chronic illnesses. Interestingly, as noted above, this is the only study using this source of identification that estimates a statistically significant effect of health insurance on job turnover. Their results suggests that health insurance reduces voluntary job turnover by about $40 \%$.

Second, one would ideally like to have a measure of expected medical care utilization or health needs, but from an econometric standpoint, such measures are generally calculated on the basis of past experience. With prime aged workers, however, past experience may not be a very reliable predictor of future outcomes. For example, in married couple families with a household head under the age of 45, a substantial fraction of physician visits and hospital admissions are pregnancy-related. In these families, last year's hospital admissions are unlikely to be very predictive of next year's medical needs. Similarly, Madrian (1994b) argues that pregnancy is one of the more prevalent health conditions among prime-aged workers that is likely to generate job- 
lock (at least in the short term), but pregnancy is unlikely to be well-predicted by health or medical care utilization in the previous year (and, if anything, is probably likely to be negatively related to these things). Thus, the likelihood of extensive measurement error in many of these variables will lead to attenuation bias.

Third, to the extent that health problems impose costs on employers, both directly in terms of increased medical costs, and indirectly in terms of the decreased productivity of workers dealing with their own or a family members health problems, employers may actually be more likely to dismiss such workers, which will bias one against finding any evidence of job-lock.

Finally, there may be endogeneity in these variables that depends on the nature of the health insurance coverage that individuals have. For example, an individual with only ownemployer-provided health insurance who plans on changing jobs may decide to take care of certain medical problems before changing jobs, while an individual with spousal health insurance as well will have less incentives to do so. Behavior of this type will bias one against finding joblock in the standard difference-in-difference framework employed in these studies.

None of the papers that have used various measures of health conditions or medical care utilization to identify job-lock have addressed any of these issues. Until it can be shown that the criticisms levied above are likely to generate only small biases in the estimates and their standard errors, however, it seems unlikely to us that they provide a compelling source of identification.

The one paper that uses a completely exogenous source of non-own-employment based health insurance is Gruber and Madrian (1994), who identify the reduction in job-lock associated with continuation of coverage mandates. Their results imply that continuation of coverage mandates increase turnover by about $10 \%$. That they estimate an increase in turnover as a result of these mandates suggests that health insurance does in fact impede job mobility. However, since continuation coverage is expensive, it is unlikely that it would alleviate the full-extent of job-lock. The estimates of Gruber and Madrian (1994), however, could be viewed as a lower bound on the extent of job-lock.

Cooper and Monheit (1993) use a two-stage procedure in which they first estimate the likelihood that an individual will gain or lose health insurance coverage if he or she changes jobs, and then identify job-lock from the inclusion of variables that measure the likelihood of gaining or losing coverage in a job turnover regression. They find that being likely to gain health insurance increases turnover by $28-52 \%$, while being likely to lose health insurance reduces turnover by 23-39\%. Anderson (1997) finds a similar effect, namely that individuals who would benefit most from obtaining health insurance coverage (because of pregnancy or disability), are more likely to change jobs. She labels this type of behavior "job-push."

Slade (1997) takes a completely different tack in his effort to identify job-lock. He first documents a substantial negative correlation between health insurance coverage and the underlying propensity of individuals to change jobs. He notes that such a correlation implies that looking directly at the effect of employer-provided health insurance on job mobility cannot be 
construed as evidence of job-lock because it will largely reflect unobserved heterogeneity in the propensity to change jobs. Much of the previous literature has recognized this potential bias, however, and indeed, this is one rationale behind the difference-in-difference estimation strategy first propounded by Madrian (1994b) to identify job lock. In one of the few departures from the difference-in-difference identification framework, Slade (1997) looks directly at the effect on job mobility of the availability of health insurance at the state-level and at state hospital room charge rates. The notion behind the first measure is that if the likelihood of obtaining health insurance in another job is high, one's current employer-provided health insurance is less valuable. The latter measure is assumed to be a proxy for the former under the presumption that higher hospital room charges will decrease the availability of health insurance. He finds little evidence that these health insurance variables impact worker turnover.

It is not clear to us that the identification strategy in Slade (1997) will really enable one to identify the effect of health insurance on job mobility. The measure of health insurance availability used is the fraction of the non-elderly population in the state covered by private health insurance. If employers base their decision about whether or not to offer health insurance on the underlying turnover propensities of the workforce because health insurance is more expensive to offer when turnover is high, then states in which mobility is high for non-insurance related reasons will have a lower rate of health insurance coverage. This spurious correlation between mobility and statewide private health insurance coverage will bias one against finding an effect of health insurance availability on job mobility even if greater insurance availability does indeed increase worker turnover. Even in the absence of such a correlation, this measure would not pick up job-lock that is generated by the exclusion of pre-existing conditions among firms that do offer health insurance.

Looking at the effect of hospital room charge for evidence of job-lock is also problematic. Higher hospital room charges may decrease the overall availability of health insurance since the price of health insurance is higher, and this might be expected to decrease mobility. However, even if the price of health insurance is higher, it is not necessarily more costly for firms to offer if firms can recoup the increased cost through lower wages. This would work to mitigate any decrease in mobility that one would expect to see from higher health care costs. Moreover, one might expect the effect of higher hospital room charges to affect mobility differently for those with and without health insurance. For those with health insurance, it becomes more valuable when health care costs are high and we would expect reduced mobility. For those without health insurance, obtaining health insurance becomes more desirable and we would expect increased mobility among those without health insurance as they seek jobs to obtain this benefit. Slade (1997) does not separate the effect of hospital room charges for these two groups, and the resulting coefficient is therefore likely to reflect these two effects that work in opposite directions.

Two other papers examine the effect of health insurance on a very specific type of job turnover, namely the transition from employment to self employment. While the self-employed receive some limited tax benefits for their health insurance purchases, they, in general, face a much higher price for health insurance in addition to the potential costs associated with 
relinquishing the health insurance provided by a current employer. The first paper on this topic, by Holtz-Eakin, Penrod and Rosen (1996), finds no effect of health insurance on the transition from employment to self-employment. However, they find no affect of most other variables on this transition either (e.g. income, race, education), so the lack of an effect for health insurance may speak more to the quality of the data than to the actual effect of health insurance. Madrian and Lefgren (1998) find some evidence that both continuation coverage and spousal health insurance increase transitions to self-employment.

The results in both of these studies, however, should be interpreted with caution. The issue of measurement error in the dependent variable is also likely to be of particular concern for transitions from employment to self-employment. Although the notional idea of "self employment" is simple enough, the empirical identification of "the self employed" is more nuanced because many individuals hold both wage/salary jobs and self employment jobs. This makes the classification of someone as a "wage/salary" worker or as a "self-employed" worker necessarily arbitrary. Madrian and Lefgren (1998) show that in the SIPP, the various schemes for classifying workers as self-employed or not self-employed result in self-employment rates that vary by a factor of $40 \%$. Defining transitions over time between these two states results in even greater variation in the resulting employment-to-self-employment transition rates, which vary in some cases by a factor of $100 \%$. For some very specific groups of individuals, they claim that the transition rate between employment and self-employment is as high as $70 \%$, something they suggest as indicative of severe misclassification in the initial categorization of individuals as employed vs. self-employed. Moreover, they suggest that the estimated effects of health insurance on self employment can be sensitive to how this specific group of individuals is treated. This raises a broader specter of doubt concerning the overall hope of identifying the true effect of health insurance on employment-to-self-employment transitions as it seems clear that any definition of such a transition will likely be subject to a significant degree of measurement error. The issues of measurement error in this case are further compounded by the relatively low, on average, transition rates from employment to self-employment. These low transition rates make it more difficult to precisely estimate any effect, even if one exists, because the frequency of transitions in the data is so small.

Overall, the literature on health insurance and job choice is more divided than that on health insurance and labor force participation. About one-third of the papers studied find that health insurance significantly impacts the job choice decisions made by workers (Cooper and Monheit, 1993; Madrian, 1994b; Gruber and Madrian, 1994; Anderson, 1997; Stroupe, Kinney and Knieser, 2000); another one-third of the papers find no significant relationship between job choice and health insurance (Mitchell, 1982; Holtz-Eakin, 1994; Penrod, 1994, Holtz-Eakin, Penrod and Rosen, 1996; Slade, 1997; Kapur, 1998; Spaulding, 1997); and the remaining third find evidence that varies by empirical specification or the sub-group analyzed, or effects that are not statistically significant at standard levels (Buchmueller and Valletta, 1996; Brunetti, et al. 2000; Madrian and Lefgren, 1998; Berger, Black and Scott, 2001; Gilleskie and Lutz, forthcoming). Given the differences in identification and data, it is interesting that a fair number of the studies that find a significant effect of health insurance on job choice obtain estimates that are fairly similar in magnitude-that employer-provided health insurance reduces job mobility by 
25-50\% (Cooper and Monheit, 1993; Madrian, 1994; Buchmueller and Valletta, 1996; Stroupe, Kinney and Kniesner, 2000).

In general, using spousal health insurance to identify the effect of health insurance on job turnover results in positive and significant estimates of job-lock (Holtz-Eakin, 1994, is the notable exception, but the data concerns discussed above may explain his results). In contrast, identifying job-lock from an interaction between spousal health insurance and own health, family health, or expected medical expenditures (or a three-way interaction between these measures and own employer-provided health insurance) tends to result in statistically insignificant coefficients that are both positive and negative. Thus, the conclusion of whether or not there is job-lock seems to hinge critically on which identification strategy one finds more credible.

Our view is that the approach of using alternative sources of insurance is more credible. Both approaches suffer from potential endogeneity problems, but the health/expected expenditures approach has a host of additional difficulties that do not arise with the alternative insurance approach. Moreover, within this alternative insurance approach the research by Gruber and Madrian (1994) provides an estimate which is likely free of endogeneity bias, by using variation in state and federal continuation of coverage mandates. So a conservative approach to reading this literature would be to take the results of Gruber and Madrian (1994) identified from continuation of coverage laws as providing as lower bound $10 \%$ estimate of the magnitude of job-lock, and the results from the spousal insurance approach as providing an upper bound estimate of 25-35\% (Madrian, 1994b; Buchmueller and Valletta, 1996).

Clearly, however, the literature on health insurance and job mobility is in need of a reconciliation between the divergent results reached by the many studies on this topic. A study which made a systematic comparison of the results obtaining from using different datasets, identification strategies, and methodologies would be particularly valuable.

\section{The Missing Piece: Welfare Implications}

The review above documents the exciting approaches and important conclusions that have emerged from a decade of high quality empirical work on health insurance and the labor market. Given the relative novelty of the topic and the wide variety of empirical approaches pursued, we now have a fairly firm basis for concluding that health insurance matters for decisions such as retirement, secondary earner labor supply, and job mobility. This is no small contribution.

But, with rare exceptions discussed below, this literature has largely failed along a critical dimension: documenting, or even quite frankly discussing, the welfare implications of these results. Developing a full model of the welfare implications of job lock is beyond the scope of our current effort. But in this section we lay out the promises and pitfalls of four different approaches that might be taken to measuring the welfare implications of health-insurance induced immobility. Our discussion is written with reference to job mobility. But the points and 
conclusions carry over naturally to the welfare analysis of any model of health insurance and labor supply: the key question is the welfare consequences of a barrier to mobility from one state to another state in which utility might be higher.

\section{Approach A: Structural Modeling}

The first potential approach is to pursue a structural model of the job mobility decision, which begins with maximization of utility across job alternatives (or labor supply alternatives). The advantage of this approach to empirical estimation is that it most naturally provides a welfare framework. This is because the estimates can be tied back to fundamental utility parameters, allowing evaluation of utility in the different states, and thus a measure of the utility loss from reduced mobility.

Dey (2000) estimates a structural model of job turnover in an attempt to recover estimates of the welfare consequences of job-lock. While he suggests that job-lock does exist (he estimates a highly variable $2-16 \%$ reduction in mobility due to employer-provided health insurance), he finds very small welfare effects. It is difficult to both evaluate his results and to generalize from them. First, because it is not clear in the paper where the identification of job-lock comes from. And second, because the sample of individuals used in the estimation is individuals who were unemployed. If individuals who value employer-provided health insurance highly take steps to avoid becoming unemployed, then this sample will be comprised largely of the individuals least likely to have their labor supply decisions impacted by health insurance availability, and consequently the welfare consequences associated with changing the nature of health insurance availability for these individuals will be small. For individuals who value health insurance more highly, the welfare effects could presumably be much larger.

More generally, while estimating this type of structural model is straightforward in theory, doing so in a credible fashion is likely to prove daunting in practice. This is because the data are unlikely to contain variation sufficient to pin down all the base preference parameters required to evaluate such a utility-theoretic model. Estimating such a model would require, at a minimum, estimates of time discount rates, parameters of risk aversion, direct utility from consumption of medical care relative to cash, and the disutility of labor. As a result, any estimates derived from this approach are likely to be heavily dependent on assumptions about the functional form of the empirical model.

Moreover, this approach, as well as almost all of the others reviewed below, misses a potentially key component of the welfare gain from reducing job lock: spillovers. In increasing returns models such as that of Kremer (1993), there can be important complementarities between skilled workers that generate positive externalities from improved matches. In such a world, the gains to society from improved matches can significantly exceed the gains that would emerge from structural models focused on the worker alone.

Approach B: Computing Productivity Loss 
A second approach would be to directly use data on the value of mobility to infer the cost of this mobility restriction. This is the approach taken by Monheit and Cooper (1994), who perform a rough welfare calculation using their estimate of a the health insurance-induced reduction in job mobility. They derive the number of individuals affected by health-insurance induced job-lock and multiply this by the average wage increase that accrues to individuals who change jobs. This yields a productivity loss equal to about one-third of one percent of GDP.

But this approach raises its own difficulties. First, the information that Monheit and Cooper (1994) use on the average wage change for job switchers is quite crude. Accurately estimating the wage increase that accrues to individuals who change jobs is difficult because job change is endogenous to the wage increase that one would be likely to obtain from doing so: individuals whose wages are likely to increase if they change jobs are more likely to do so, while individuals who have found high-productivity/high-wage job matches tend to stay where they are precisely because their wages would likely fall if they went elsewhere. The labor literature on job mobility and wage changes (including Monheit and Cooper, 1994) has also focused almost exclusively on the immediate short-term changes in wages that accompany job mobility, ignoring any effects that could potentially compound (or dissipate) over time.

Another key difficulty with this approach is that wages may be a poor proxy for marginal productivity for workers in long term employment relationships. The sign of the bias is not obvious here. On the one hand, if workers have invested in firm-specific human capital, their wage may be below their marginal product at their current firm, but above their marginal product on an alternative job. On the other hand, if there are workplace norms or some other reason for apparently inefficient long term contracts, then workers' wages may be above their marginal product at the current firm. Moreover, there is once again the important issue that there may be impacts beyond the worker themselves; if there are positive complementarities in production, then a worker's own wage would once again understate his or her marginal product. Finally, while potentially useful for thinking about job mobility, this approach is not helpful for thinking about the welfare implications of labor supply decisions that are distorted by health insurance because it does not speak at all to the value of leisure.

\section{Approach C: Bounding by the Cost of Mobility}

Another approach is to infer an upper bound on the cost of job lock (or other labor supply restrictions) by noting that these costs are limited by the cost of purchasing insurance to cover the health insurance loss induced by job change, retirement, or labor force exit. That is, so long as insurance is available at some price for purchase by the individual, then the welfare gain from the passed-up job change can't be infinitely large; at some appreciably high level, individuals would simply purchase the insurance on their own and change jobs. So, in principle, the cost of the alternative form of insurance can be used to bound the costs of job lock. ${ }^{23}$ This approach has the

\footnotetext{
${ }^{23} \mathrm{We}$ are grateful to Sherry Glied for suggesting this point to us.
} 
appealing feature that it is "market based" and incorporates the full utility costs of job lock, putting a dollar bound on those costs.

In practice, this approach has important limitations as well. The first is positing the cost of the alternative insurance option. For the first 18 months, this cost is well-bounded by the costs of COBRA (at least for those workers eligible for COBRA coverage, namely those in medium and large firms). So, for example, this approach can clearly be used to assess the loss from retirement lock among those more than 63.5 years old. But for other groups, after 18 months the cost of alternative health insurance rises to the that of purchasing a policy on the nongroup market. These costs are not well defined, for two reasons. First, nongroup policies are typically much less generous than policies provided in the group market. Second, nongroup premiums are much more variable, and there is no guarantee of a long-term premium. So if an individual becomes ill, his or her premium could rise exponentially. In states with high risk pools or some other insurance backstop, there is a limit to how high premiums can get, but even this limit is subject to the political risk that the high risk pool subsidy may end.

Another issue with this approach is liquidity constraints. Take the case of a worker considering an alternative position that will result in higher productivity but that provides only delayed compensation (such as stock options at a startup firm). In this case, neither the firm nor the worker may have much cash up front. Even if there is a reasonably priced insurance alternative, the firm and the employee may jointly be unable to front the funds to purchase that insurance.

Despite these limitations, this approach lends itself to some fairly straightforward limit calculations. For the first 18 months, assuming full shifting of insurance costs to wages, insurance has the same gross cost on the current job as on any new job, due to COBRA. Of course, since employer insurance payments are tax deductible but own insurance payments are not, there is a net cost of moving from the current group onto COBRA coverage of one's tax rate times the insurance costs. After the first 18 months, we have the difficulty of pricing nongroup coverage, but for almost all non-elderly persons such coverage should be available at no more than $50 \%$ higher than the current group coverage cost

This bounding approach suggests very modest costs of job lock. For example, suppose that current nongroup coverage for a family costs $\$ 6000$ per year, of which the employee is already paying $\$ 2000$. Suppose that a worker has a tax rate on wages of $35 \%$ (a $15 \%$ federal rate, $15 \%$ payroll tax rate, and 5\% state rate). Then if he leave his current job for another job on which he must purchase insurance, the net cost to him is the $\$ 1400$ in lost tax subsidy on the health insurance for 18 months, and at most $\$ 4400$ per year (the loss in the tax subsidy plus the differential cost of the nongroup policy) thereafter. 
There are currently roughly 50 million married workers covered by health insurance on their job. ${ }^{24}$ Suppose that each year, job-lock accounts for a reduction in job mobility of $25 \%$, or 4 percentage points, so that 2 million (50 million * 0.04) workers are "affected" by job lock. ${ }^{25}$ The maximum cost of job lock, in steady state, is therefore between $\$ 3$ and $\$ 9$ billion per year. These costs are between $0.03 \%$ and $0.09 \%$ of GDP, which is fairly small, particularly relative to the $\$ 100$ billion plus price-tag for any comprehensive reform to eliminate the problem of the uninsured in America.

Admittedly, this is a very crude calculation. First and foremost, it is in theory only an upper bound. Such an approach may be more useful for ruling out very large welfare losses than for putting an actual cost estimate on job lock. On the other hand, much of the welfare loss from job lock may be due to very high cost workers for whom nongroup insurance coverage is not available or for whom such coverage is more expensive than we assume above. If so, this approach would instead lead us to dramatically understate the welfare losses due to job lock. Moreover, the lack of long-term health insurance contracts in the nongroup market, and the resulting variability in premiums over time, may mean that nongroup health insurance coverage is not an attractive option even if the immediate costs are modest relative to the higher wages that can be obtained on a new job. Finally, this approach continues to suffer from the limitation that it misses any spillover effects of productivity improvements, which implies that even this "upper bound" may be understated.

\section{Approach D: Examining Impacts of Loosening Job Lock}

Another potential approach is to examine the impact on labor market outcomes of interventions that reduce job lock. That is, suppose that there is an exogenous change which suddenly removes the possibility of job lock for a worker or class of workers. Then, if there is an important productivity impact of job lock, we should see productivity rise when this change occurs. Moreover, this approach holds out the only possibility for getting at the spillovers concern which plagues all of the approaches above. Analysis at the market level of a market wide change which reduces job lock would allow for a calculation which incorporates any spillover effects.

An analysis in this spirit is carried out by Gruber and Madrian (1997). A clean example of an intervention that reduces job lock is a continuation of coverage mandate. Gruber and Madrian model the reemployment earnings of job leavers as a function of whether continuation coverage is available and examine whether such coverage improves subsequent job matches. They find that one year of continuation coverage availability doubles the reemployment earnings of job leavers who take up that coverage.

\footnotetext{
${ }^{24}$ Authors' tabulations from March 2000 Current Population Survey.

${ }^{25}$ Madrian (1994b) reports that $16 \%$ of her sample changed jobs over an approximately $12-$ month period. A $25 \%$ reduction in mobility using this is a baseline implies a 4 percentage point decrease in turnover.
} 
This is an enormous estimate which bears confirmation. ${ }^{26}$ In particular, these effects seem very large relative to the bounds established above. In the data used by Gruber and Madrian, the typical reemployment earnings are roughly $\$ 15,000$ per year. So the implication is that providing insurance at the average group cost, even for only 18 months, allowed unemployed workers more time to search for jobs, resulting in earnings that increased by $\$ 15,000$.

Extrapolating a gain of this magnitude to the 2 million job locked married workers in the U.S. would cause earnings to rise by $\$ 30$ billion. But this is an upper bound because those individuals who take continuation coverage are likely to be those who have the least access to an attractive nongroup product. And even this figure is not enormous relative to the size of the economy.

On the other hand, even this large estimate does not account for any spillover effects. As noted above, this is the one approach that does hold out some hope for measuring spillover effects, as one can examine aggregate impacts of changes that reduce job lock. But such an examination would require a very large loosening for the aggregate impact to be detectable.

This approach is also potentially useful for looking at labor supply effects, as Gruber and Madrian (1995) illustrate for the case of retirement. In that paper, they find that a year of continuation coverage raises the retirement hazard by $30 \%$. They then note that this effect can be implicitly "dollarized" through comparisons to estimates of the impact of pension wealth on retirement. Doing so, they find that a year of continuation coverage for an older worker has the same impact on retirement as $\$ 13,600$ in pension wealth. They also use data on the expected distribution of medical expenses to note that this large dollar value is not inconsistent with a relatively low coefficient of relative risk aversion of 2 , given the highly variable medical costs facing an older person retiring uninsured.

\section{Conclusion}

The past decade has witnessed the development of a large and exciting literature on health insurance, labor supply, and job mobility. Of the 50+ papers reviewed here, only 1 was written before 1990. As with any large literature, there are few conclusions on which there is unanimous agreement. But, relative to other areas, it appears to us that there are some fairly clear conclusions that can be derived from this set of studies:

1) Health Insurance is Quite Important for Retirement Decisions: The question on which there is probably the greatest consensus is that health insurance is a key determinant of the decision to retire. This is perhaps not surprising given the high and variable level of medical costs for those near the age of Medicare eligibility. The studies reviewed suggest that the availability of retiree health insurance raises the odds of

\footnotetext{
${ }^{26}$ Gruber and Madrian (1997) do try to internally test this estimate by, for example, showing that there is no effect on the earnings of those who do not separate.
} 
retirement by $30-80 \%$. This consistent conclusion emerges from very different approaches using very different data sets.

2) Health Insurance is Not Very Important for The Labor Supply Decisions of Low Income Mothers: While there is some debate over whether or not there is a statistically significant impact of health insurance availability on labor supply decisions for low income mothers, there appears to be a fairly general consensus that such effects, if they exist, are not large.

3) Health Insurance Appears to be Important for the Labor Supply Decisions of Married Women: The much smaller literature on health insurance and the labor supply of married women is remarkably consistent in its conclusion that health insurance is important. But our confidence in this conclusion is tempered by the fact these small number of studies are relatively similar, and all suffer from the fact that the identification strategy used (assuming the exogneity of the husband's health insurance) is contestable.

4) Alternative Health Insurance Coverage is Important for Job Mobility, Implying Significant Job Lock: As we have discussed at length, there is a true "schism" in the job lock literature. With rare exception, those studies that proxy for the value of health insurance using a measure of alternative sources of coverage (mostly spousal insurance) find sizeable and significant estimates of job lock. Those studies that use health spending as a proxy for the value of health insurance find little evidence of job lock. Our own view is that the former approach to studying job lock has much more to recommend it, given the endogeneity and mismeasurement of expected medical spending. So our view is that there is on net strong evidence for job lock.

5) There is Much Work to be Done on Welfare Implications: Empirical work has run vastly ahead of theory in this area, and no where is that more evident than in the lack of work, and even lack of attention, to welfare issues. We have discussed four approaches to moving forward on the measurement of the welfare implications of job lock, but much more work needs to be done on each of them. To the extent that these frameworks are useful, they suggest that the economic costs of job lock may be modest.

To summarize, we have learned a lot about the effect of health insurance on both labor supply and job mobility over the past ten years, but relatively little about the implications of these results. Clearly, this is where the literature in this area needs to be heading as we embark on the next decade of work. 


\section{References}

Anderson, Patricia M. (1997). "The Effect of Employer-Provided Health Insurance on Job Mobility: Job-Lock or Job-Push?," unpublished paper (Dartmouth University).

Bazzoli, Gloria J. (1985). "The Early Retirement Decision: New Empirical Evidence on the Influence of Health," Journal of Human Resources 20(2): 214-234.

Bound, John (1989). "The Health and Earnings of Rejected Disability Applicants," American Economic Review 79(3): 482-503.

Berger, Mark C. et al. (2000). "Spouse Health Insurance and the Retirement Decision," unpublished paper (University of Kentucky).

Berger, Mark C., Dan A. Black and Frank A. Scott (2001). "Is There Job-Lock?," unpublished paper (University of Kentucky).

Blank, Rebecca M. (1989). "The Effect of Medical Need and Medicaid on AFDC Participation," Journal of Human Resources 24:54-87.

Blau, David M. and Donna B. Gilleskie (2001a). "Retiree Health Insurance and Labor Force Behavior of Older Men in the 1990s," Review of Economics and Statistics 83 (1): 64-80.

Blau, David M. and Donna B. Gilleskie (2001b). "Health Insurance and Retirement of Married Couples," unpublished paper (University of North Carolina).

Brown, James N. and Audrey Light, (1992). "Interpreting Panel Data on Job Tenure," Journal of Labor Economics 10(3): 219-57.

Brunetti, Michael A. et al. (2000). "Health Status, Health Insurance, and Worker Mobility: A Study of Job Lock in California," unpublished Paper (University of California Berkeley, UC DATA/Survey Research Center).

Buchmueller, Thomas C. and Robert G.Valletta (1999). "The Effect of Health Insurance on Married Female Labor Supply," Journal of Human Resources 34(1): 42-70.

Buchmueller, Thomas.C. and Robert G. Valletta (1996), "The Effects of Employer-Provided Health Insurance on Worker Mobility," Industrial and Labor Relations Review 49(3): 439-455.

Chou, Y. J. and Douglas Staiger (2001). "Health Insurance and Female Labor Supply in Taiwan," Journal of Health Economics, 20(2): 187-211. 
Chou, Shin-Yi and Jin-Tan Liu (2000). "National Health Insurance and Female Labor Supply: Evidence from Taiwan," unpublished paper (New Jersey Institute of Technology).

Congressional Research Service (1988). Costs and Effects of Extending Health Insurance Coverage (Government Printing Office, Washington DC).

Cooper, Philip F. and Alan C. Monheit (1993). "Does Employment-Related Health Insurance Inhibit Job Mobility?," Inquiry 30(4): 400-416.

Currie, Janet and Brigitte C. Madrian (1999). "Health, Health Insurance, and the Labor Market," in Orley Ashenfelter and David Card, eds., Handbook of Labor Economics, Volume 3, (Elsevier Science: Amsterdam) 3309-3416.

Currie, Janet and Jonathan Gruber (1996a). "Saving Babies: The Efficacy and Cost of Recent Changes in the Medicaid Eligibility of Pregnant Women," Journal of Political Economy 104(6): 1263-96.

Currie, Janet and Jonathan Gruber (1996b). "Health Insurance Eligibility, Utilization of Medicare Care, and Child Health," Quarterly Journal of Economics 111(2): 431-66.

Cutler, David M. (1994). "Market Failure in Small Group Health Insurance," NBER Working Paper No. 4879 (National Bureau of Economic Research: Cambridge, MA).

Decker, Sandra L. (1993). "The Effect of Medicaid on Access to Health Care and Welfare Participation." Ph.D. Dissertation, Harvard University.

Dey, Matthew S. (2000). "Welfare and Mobility Effects of Employer-Provided Health Insurance," unpublished paper (University of Chicago).

Diamond, Peter A. and Jerry A. Hausman (1984). "The Retirement and Unemployment Behavior of Older Men," in Henry Aaron and Gary Burtless, eds., Retirement and Economic Behavior (Brookings Institution: Washington DC) 97-134.

Ellwood, David and Kathleen Adams (1990). "Medicaid Mysteries: Transitional Benefits, Medicaid Coverage, and Welfare Exits," Health Care Financing Review, 1990 Annual Supplement, 119-131.

Employee Benefit Research Institute (1990). Employee Benefit Notes, November 1990 (Employee Benefit Research Institute: Washington DC).

Employee Benefit Research Institute (2000). Sources of Health Insurance and Characteristics of the Uninsured (Employee Benefit Research Institute: Washington DC). 
French, Eric and John Bailey Jones (2001). "The Effects of Health Insurance and Self-Insurance on Retirement Behavior." Unpublished paper (Federal Reserve Bank of Chicago).

Fronstin, Paul (1996). Sources of Health Insurance and Characteristics of the Uninsured, EBRI Issue Brief No. 179 (Employee Benefit Research Institute: Washington DC).

Gilleskie, Donna B. and Brian Lutz (forthcoming). "The Impact of Employer-Provided Health Insurance on Dynamic Employment Transitions," Journal of Human Resources.

Gruber, Jonathan (1994). “The Incidence of Mandated Maternity Benefits," American Economics Review, 84(3): 622-41.

Gruber, Jonathan (2000). "Health Insurance and the Labor Market," in Anthony J. Culyer and Joseph P. Newhouse, eds., Handbook of Health Economics Volume 1, (Elsevier Science: Amsterdam), 645-706.

Gruber, Jonathan and Brigitte C. Madrian (1994). "Health Insurance and Job Mobility: The Effects of Public Policy on Job-Lock," Industrial and Labor Relations Review 48(1): 86-102.

Gruber, Jonathan and Brigitte C. Madrian (1995). "Health Insurance Availability and the Retirement Decision," American Economic Review 85(4): 938-948.

Gruber, Jonathan and Brigitte C. Madrian (1996). "Health Insurance and Early Retirement: Evidence from the Availability of Continuation Coverage," in D.A. Wise, ed., Advances in the Economics of Aging (University of Chicago Press, Chicago) 115-143.

Gruber, Jonathan and Brigitte C. Madrian (1997). "Employment Separation and Health Insurance Coverage," Journal of Public Economics 66(3): 349-382.

Gustman, Alan L. and Thomas L. Steinmeier (1994). "Employer-Provided Health Insurance and Retirement Behavior," Industrial and Labor Relations Review 48(1): 124-140.

Ham, Jon and Lara Shore-Sheppard (2000). "The Impact of Public Health Insurance on Labor Market Transitions," unpublished paper (Ohio State University).

Hausman, Jerry A., Abrevaya, Jason and Fiona M. Scott Morton (1998). "Misclassification of the Dependent Variable in a Discrete-Response Setting," Journal of Econometrics 87(2): 239-69.

Headen, Jr., Alvin E., Robert L. Clark, and Linda Shumaker Ghent (1997). "Effects of Retiree Health Insurance and Pension Coverage on the Retirement Timing of Older Workers: Sensitivity of Estimates," unpublished paper (North Carolina State University). 
Holtz-Eakin, Douglas (1994), "Health Insurance Provision and Labor Market Efficiency in the United States and Germany," in Rebecca.M. Blank, ed., Social Protection Versus Economic Flexibility: Is There a Tradeoff? (University of Chicago Press: Chicago) 157187.

Holtz-Eakin, Douglas, John R. Penrod, and Harvey S. Rosen (1996). "Health Insurance and the Supply of Entrepreneurs," Journal of Public Economics 62(1-2): 209-235.

Hurd, Michael and Kathleen McGarry (1996). "Prospective Retirement: Effects of Job Characteristics, Pensions, and Health Insurance," unpublished paper (University of California at Los Angeles).

Johnson, Richard W., Amy J. Davidoff and Kevin Perese (1999). "Health Insurance Costs and Early Retirement Decisions," unpublished paper (The Urban Institute: Washington D.C.)

Kapur, Kanika. (1998). "The Impact of Health on Job Mobility: A Measure of Job Lock," Industrial and Labor Relations Review 51(2): 282-297.

Karoly, Lynn A. and Jeannette A. Rogowski (1994). "The Effect of Access to Post-Retirement Health Insurance on the Decision to Retire Early," Industrial and Labor Relations Review 48(1): 103-123.

Kremer, Michael (1993). "The O-Ring Theory of Economic Development," Quarterly Journal of Economics, 108(3): 551-576.

Lumsdaine, Robin L., James H. Stock, and David A. Wise (1994), "Pension Plan Provisions and Retirement: Men and Women, Medicare, and Models" in David A. Wise, ed., Studies in the Economics of Aging (University of Chicago Press, Chicago) 183-220.

Madrian, Brigitte C. (1994a). "The Effect of Health Insurance on Retirement," Brookings Papers on Economic Activity, 1994 1, 181-232.

Madrian, Brigitte C. (1994b). "Employment-Based Health Insurance and Job Mobility: Is There Evidence of Job Lock?," Quarterly Journal of Economics 109(1): 27-54.

Madrian, Brigitte C. and Nancy D. Beaulieu (1998). "Does Medicare Eligibility Affect Retirement?" in David A. Wise, ed., Inquiries in the Economics of Aging (University of Chicago Press: Chicago) 109-131.

Madrian, Brigitte C. and Lars John Lefgren (1998). "The Effect of Health Insurance on Transitions to Self Employment," unpublished paper (University of Chicago).

McDonnell, Ken and Paul Fronstin (1999). EBRI Health Databook (Employee Benefit Research Institute: Washington DC). 
Meyer, Bruce D. and Dan T. Rosenbaum (2001). "Welfare, The Earned Income Tax Credit, and the Labor Supply of Single Mothers," Quarterly Journal of Economics 116(3): 10631114.

Meyer, Bruce D. and Dan T. Rosenbaum (2000a). "Making Single Mothers Work: Recent Tax and Welfare Policy and Its Effect," National Tax Journal 53(4): 1027-1061.

Meyer, Bruce D. and Dan T. Rosenbaum (2000b). "Medicaid, Private Health Insurance, and the Labor Supply of Single Mothers," unpublished paper (Northwestern University).

Mitchell, Olivia S. (1982). "Fringe Benefits and Labor Mobility," Journal of Human Resources $17(2): 286-298$.

Moffitt, Robert and Barbara L. Wolfe (1992). "The Effect of the Medicaid Program on Welfare Participation and Labor Supply," Review of Economics and Statistics 74(4): 615-626.

Monheit, Alan C. and Philip F. Cooper (1994). "Health Insurance and Job Mobility: Theory and Evidence," Industrial and Labor Relations Review 48(1): 68-85.

Monheit, Alan C., et al. (1985). "The Employed Uninsured and the Role of Public Policy," Inquiry 22(4): 348-364.

Montgomery, Edward and John C. Navin (2000). "Cross-State Variation in Medicaid Program and Female Labor Supply," Economic Inquiry 38(3): 402-18.

Olson, Craig A. (1998). "A Comparison of Parametric and Semiparametric Estimates of the Effect of Spousal Health Insurance Coverage on Weekly Hours Worked by Wives," Journal of Applied Econometrics, 13(5): 543-565.

Penrod, John R. (1994). "Empirical Essays in the Economics of Labor and Health." Ph.D. Dissertation, Princeton University.

Peracchi, France and Finis Welch (1994). "Trends in Labor Force Transitions of Older Men and Women," Journal of Labor Economics 12(2): 210-42.

Perreira, Krista M. (1999). "Exits, Recidivism, and Caseload Growth: The Effect of Private Health Insurance Markets on the Demand for Medicaid." Ph.D. Dissertation, University of California Berkeley.

Rogowski, Jeannette A. and Lynn A. Karoly (2000). "Health Insurance and Retirement Behavior: Evidence from the Health and Retirement Survey." Journal of Health Economics, 19 (4): 529-39. 
Rosen, Sherwin (1986). "The Theory of Equalizing Differences," in Orley Ashenfelter and Richard Layard, eds. Handbook of Labor Economics, Volume 1, 641-692.

Ruhm, Christopher J. (1990), "Bridge Jobs and Partial Retirement," Journal of Labor Economics 8(4): 482-501.

Rust, John and Christopher Phelan (1997), "How Social Security and Medicare Affect Retirement Behavior in a World of Incomplete Markets," Econometrica 65(4): 781-831.

Schone, Barbara Steinberg and Jessica Primoff Vistnes (2000). "The Relationship Between Health Insurance and Labor Force Decisions: An Analysis of Married Women," unpublished Paper (Agency for Healthcare Research and Quality).

Sheiner, Louise (1999). "Health Care Costs, Wages and Aging," Finance and Economics Discussion Series 99/19 (Board of Governors of the Federal Reserve System: Washington, DC).

Slade, Eric P. (1997). "The Effect of the Propensity to Change Jobs on Estimates of 'JobLock'," unpublished paper (Johns Hopkins University).

Spaulding, James Wallace (1997). "Fringe Benefits, Job Quality, and Labor Mobility: Pension and Health Insurance Effects on Job-Change Decisions." Ph.D. Dissertation, University of Wisconsin-Madison.

Stern, Steven (1989). "Measuring the Effect of Disability on Labor Force Participation," Journal of Human Resources 24(3): 361-395.

Stroupe, Kevin T., Eleanor D. Kinney and Thomas J. Kniesner (2000). "Chronic Illness and Health Insurance-Related Job Lock," Center for Policy Research Working Paper No. 19, Maxwell School of Citizenship and Public Affairs, Syracuse University, Syracuse, New York.

Wellington, Allison J. and Deborah A. Cobb-Clark (2000). "The Labor-Supply Effects of Universal Health Coverage: What Can We Learn From Individuals with Spousal Coverage?," in Simon W. Polachek, ed., Worker Well-Being: Research in Labor Economics, Volume 19 (Elsevier Science: Amsterdam).

Winkler, Anne E. (1991). "The Incentive Effects of Medicaid on Women's Labor Supply," Journal of Human Resources 26(2): 308-337.

Wolfe, Barbara L. and Steven C. Hill (1995). "The Effect of Health on the Work Effort of Single Mothers," Journal of Human Resources 30(1): 42-62. 
Yazici, Esel Y. (1997). "Consequences of Medicaid Expansions on Three Outcomes: Demand for Private Insurance, Infant and Child Health, and Labor Supply." Ph.D. Dissertation, City University of New York.

Yelowitz, Aaron.S. (1995). "The Medicaid Notch, Labor Supply and Welfare Participation: Evidence from Eligibility Expansions," Quarterly Journal of Economics 110(4): 909-940.

Yelowitz, Aaron S. (1996). "Did Recent Medicaid Reforms Cause the Caseload Explosion in the Food Stamp Program?" UCLA Working Paper \#756, July 1996; IRP Discussion Paper 1109-96.

Yelowitz, Aaron S. (1998a). "The Impact of Health Care Costs and Medicaid on SSI Participation.” In Growth in Disability Benefits: Explanation and Policy Implications, Kalman Rupp and David C. Stapleton, eds. (Kalamazoo, MI: W. E Upjohn Institute for Employment Research).

Yelowitz, Aaron S. (1998b). "Why Did the SSI-Disabled Program Grow So Much? Disentangling the Effect of Medicaid," Journal of Health Economics 17(3): 321-350.

Yelowitz, Aaron S. (1998c). "Evaluating the Effects of Medicaid on Welfare and Work: Evidence from the Past Decade," unpublished paper (University of California Los Angeles).

Yelowitz, Aaron S. (2000). "Using the Medicare Buy-In Program to Estimate the Effect of Medicaid on the SSI Participation," Economic Inquiry 38(3): 419-441. 


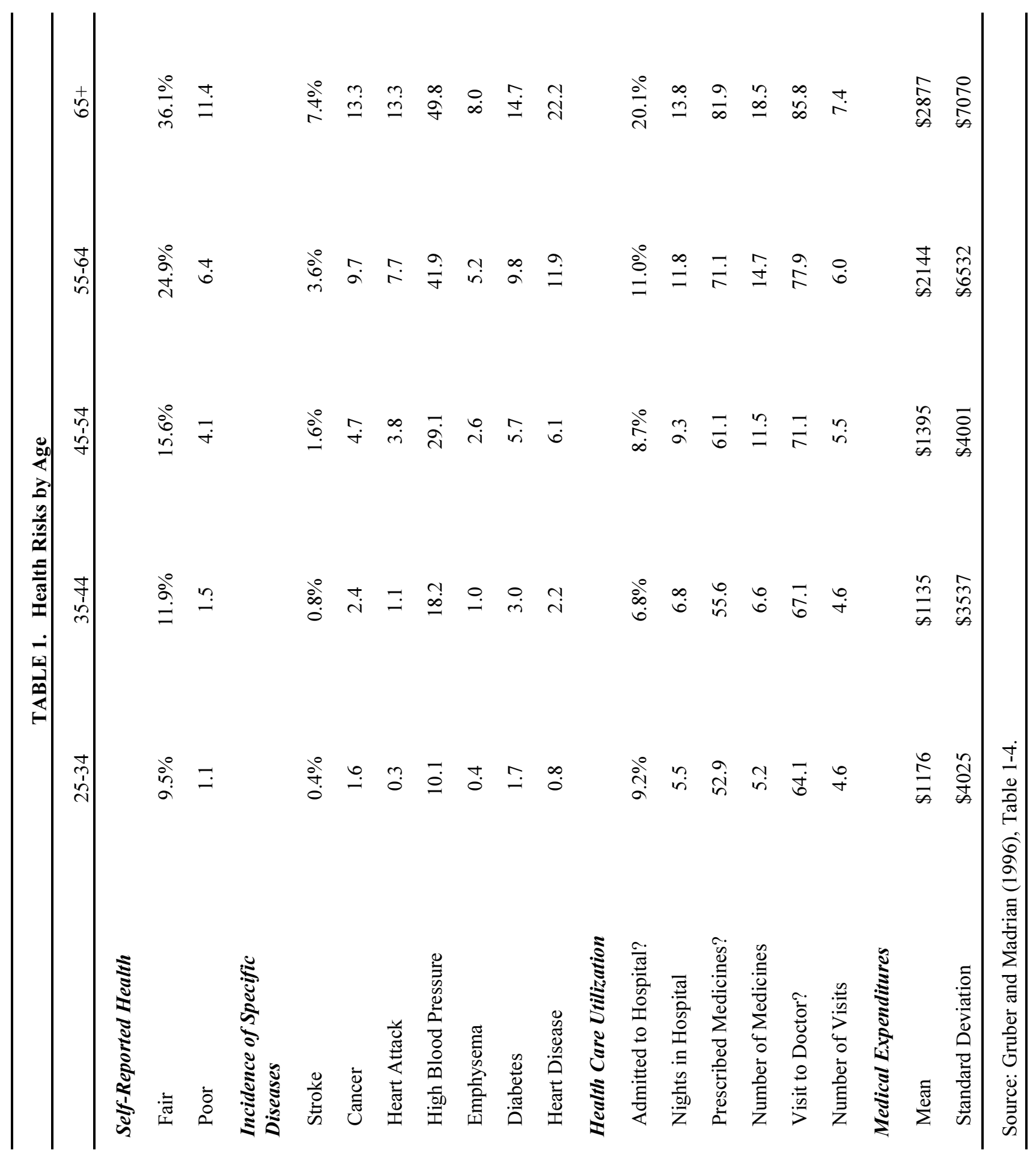




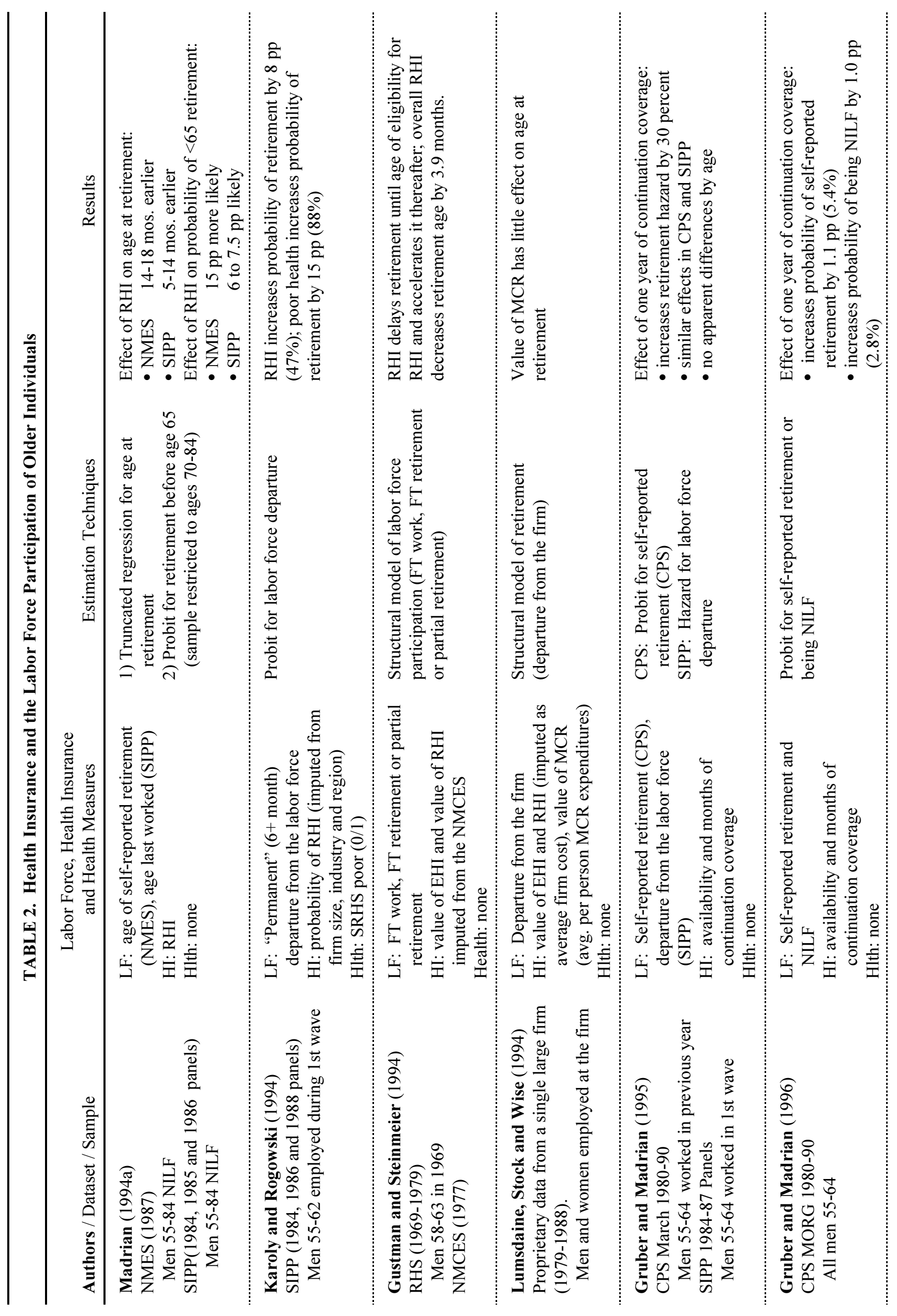




\begin{tabular}{|c|c|c|c|c|c|}
\hline 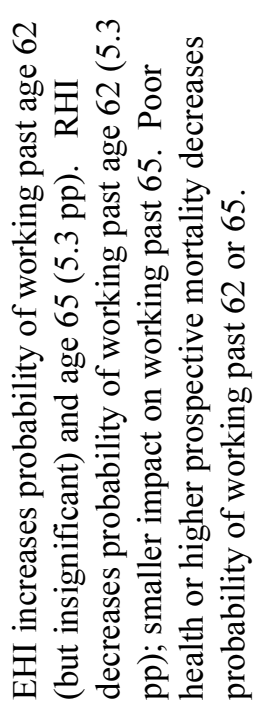 & 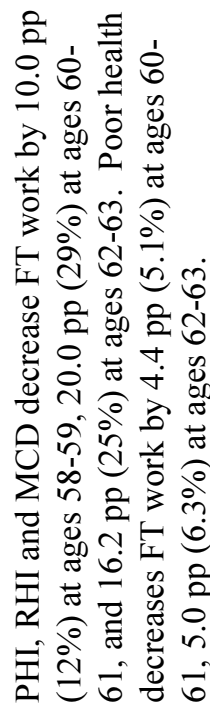 & 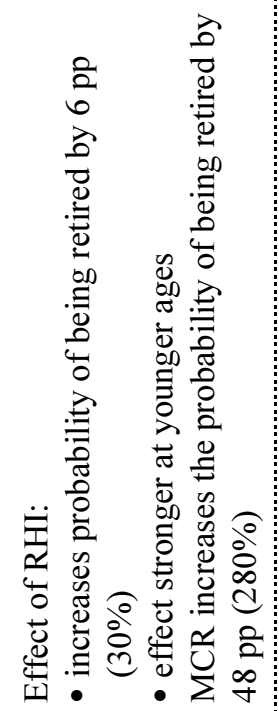 & 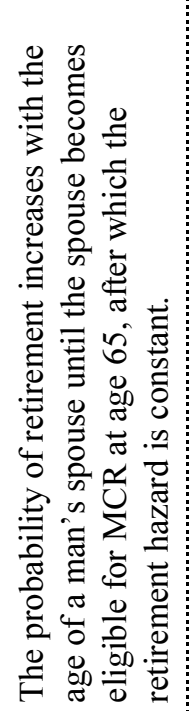 & 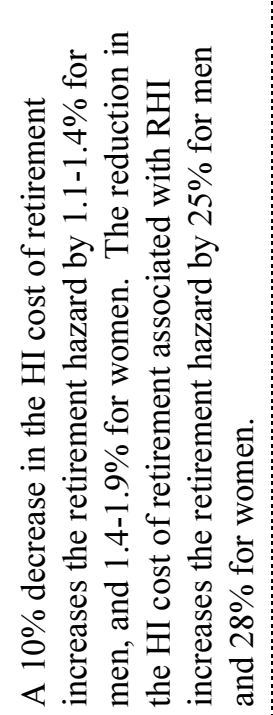 & 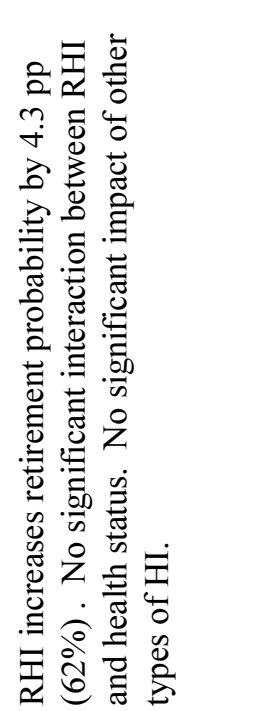 \\
\hline 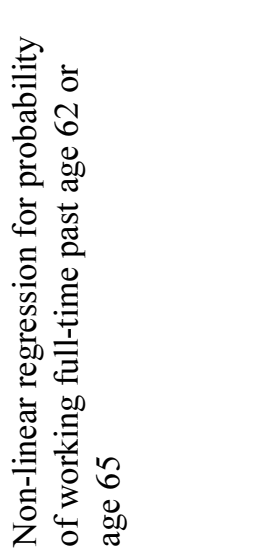 & 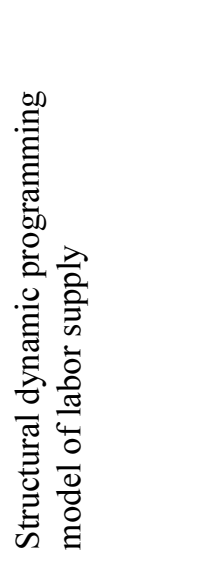 & 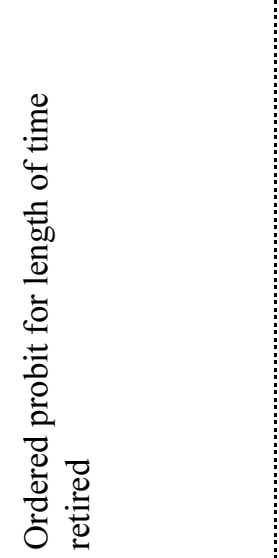 & 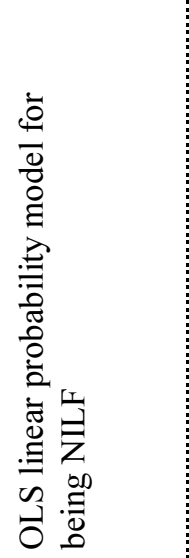 & 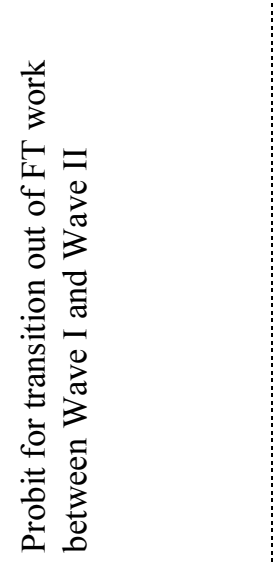 & 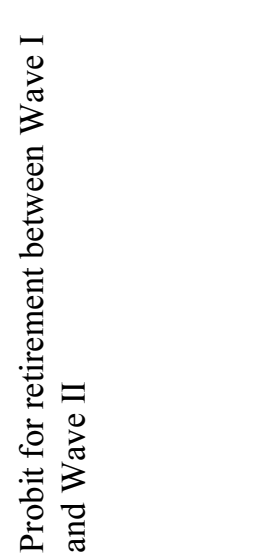 \\
\hline 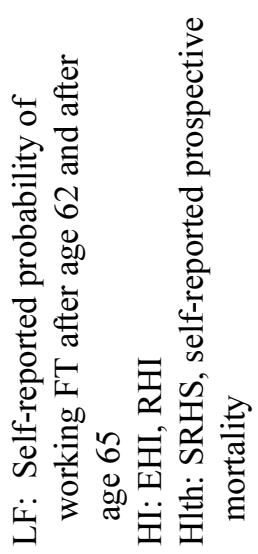 & 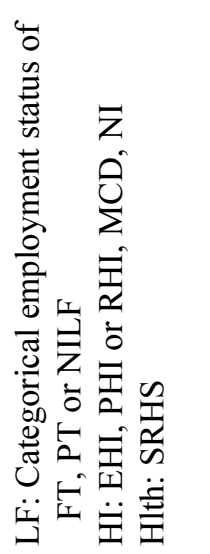 & 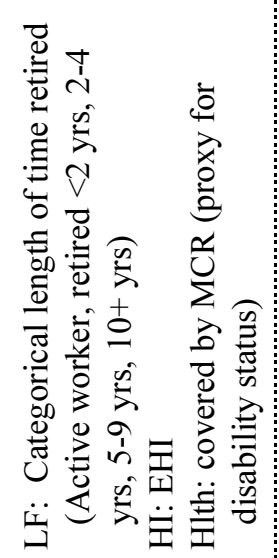 & 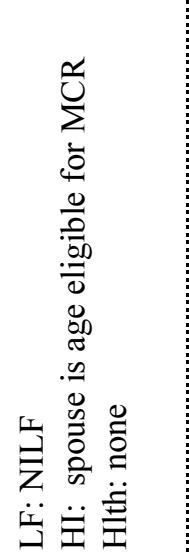 & 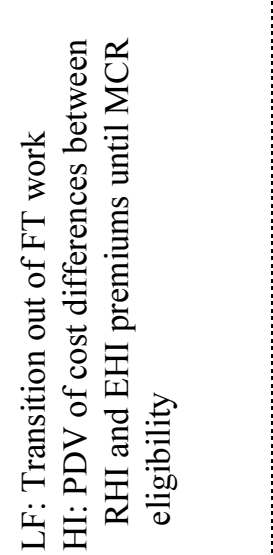 & 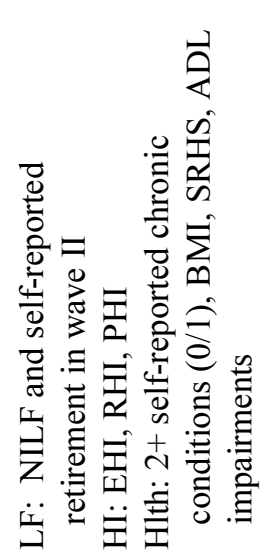 \\
\hline 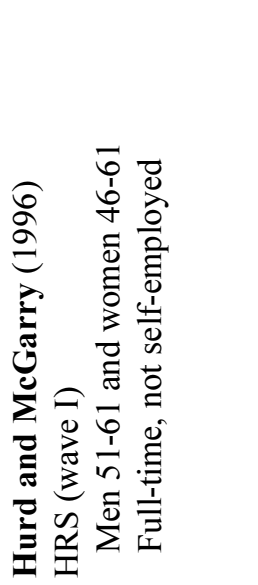 & 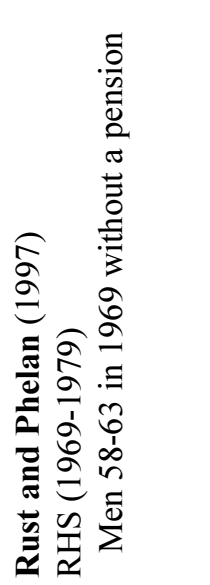 & 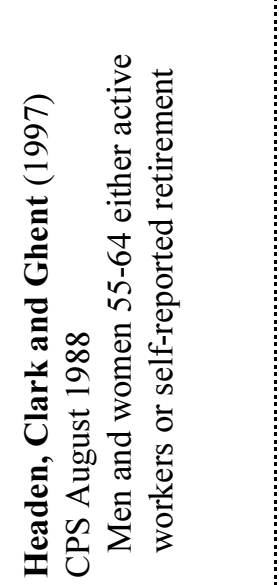 & 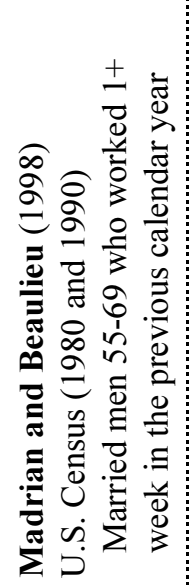 & 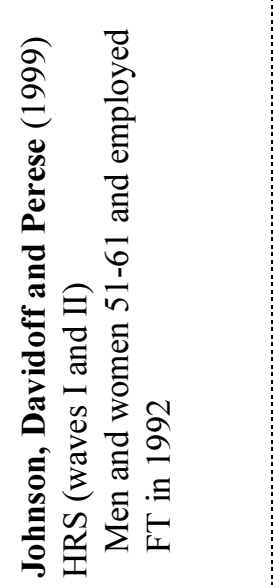 & 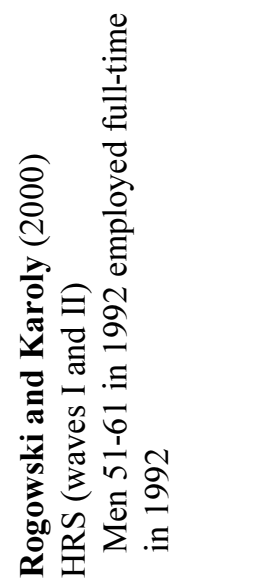 \\
\hline
\end{tabular}




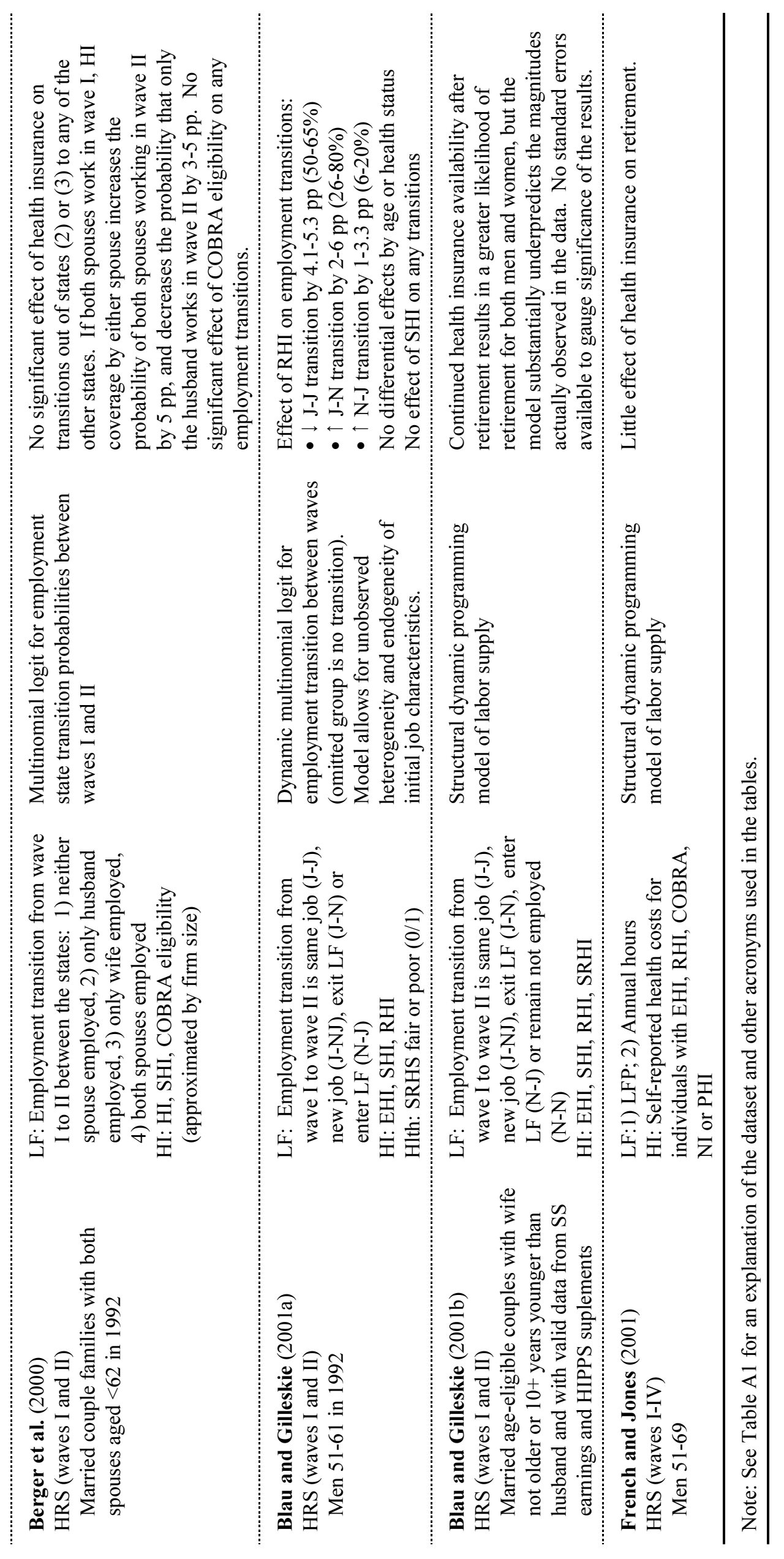




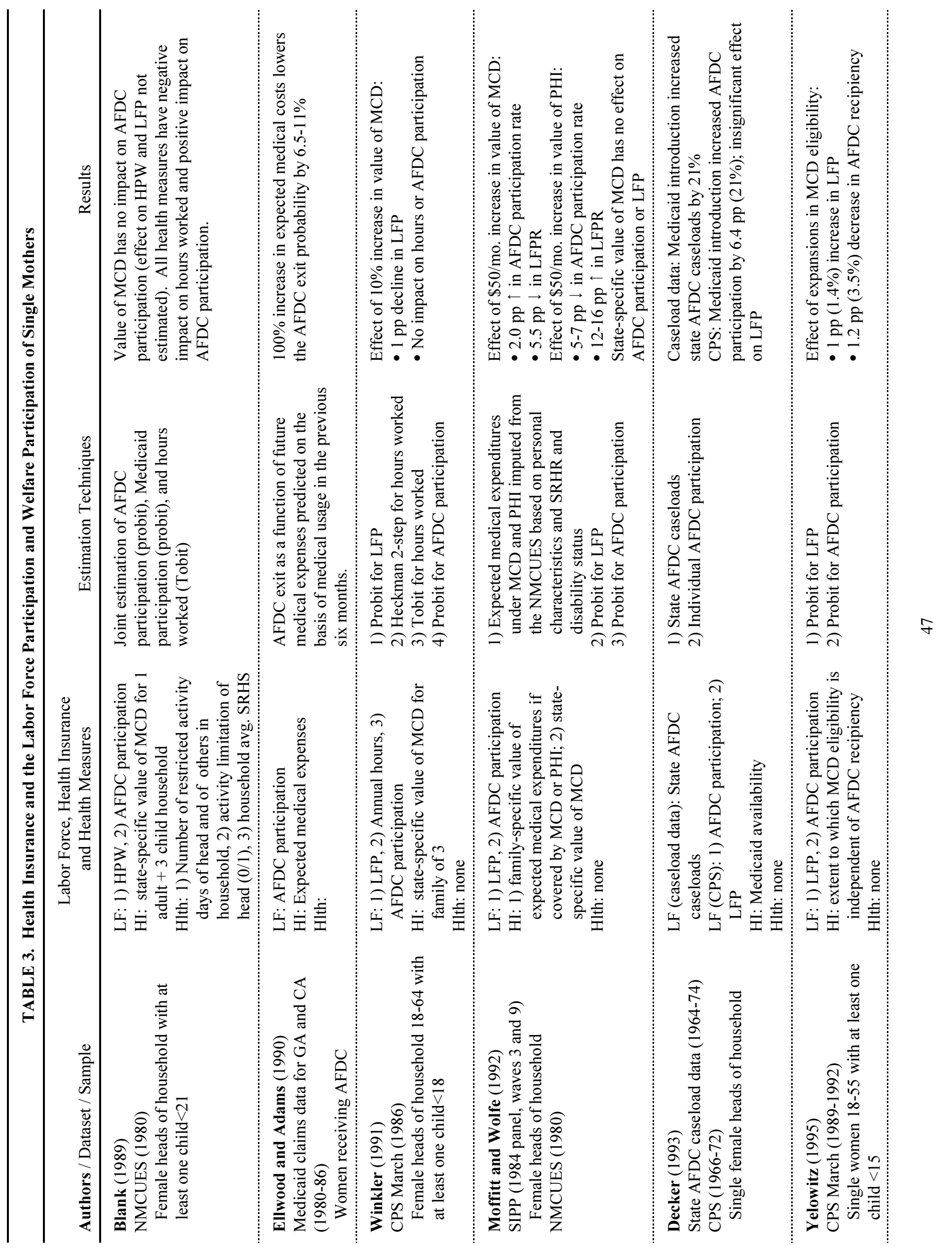




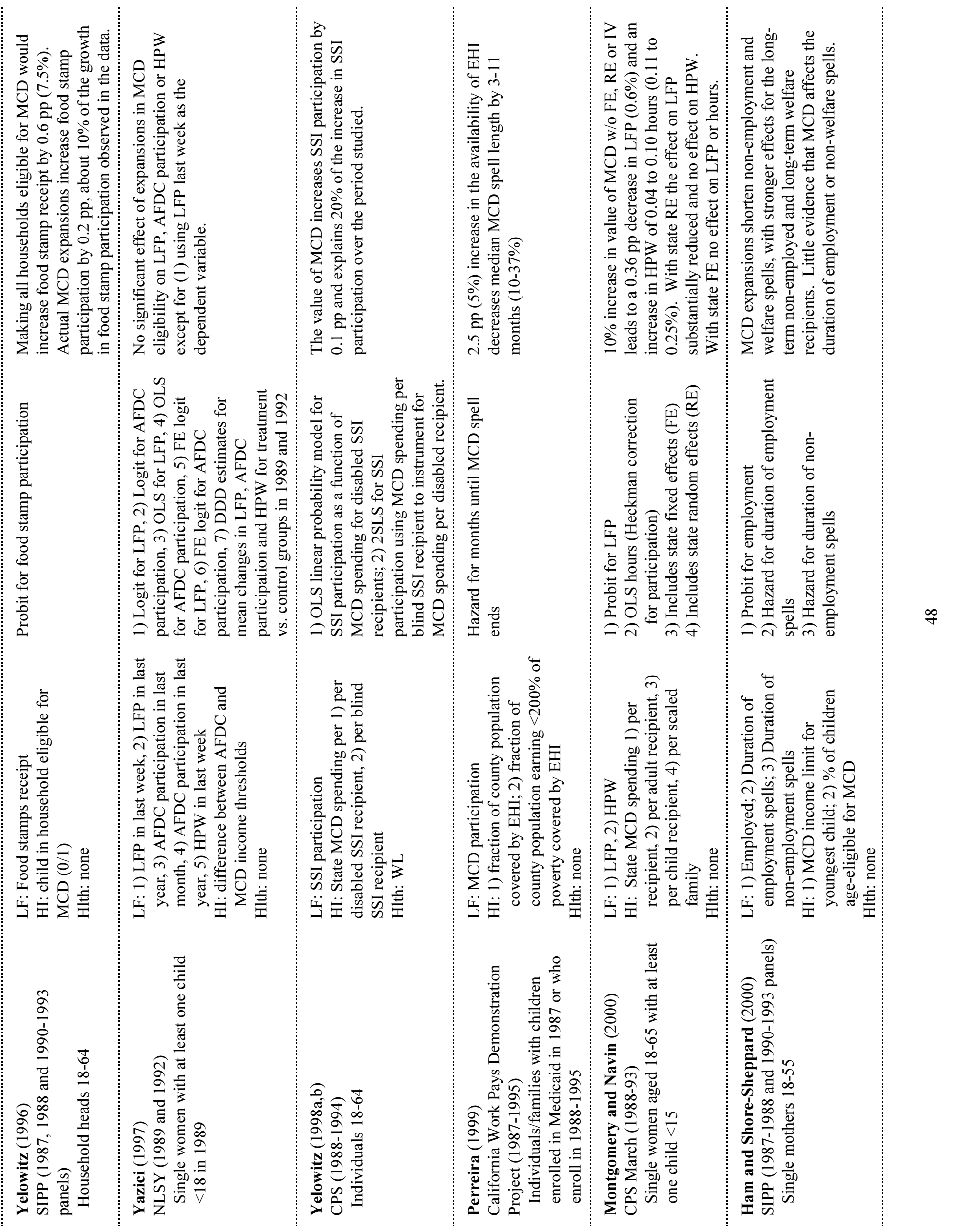




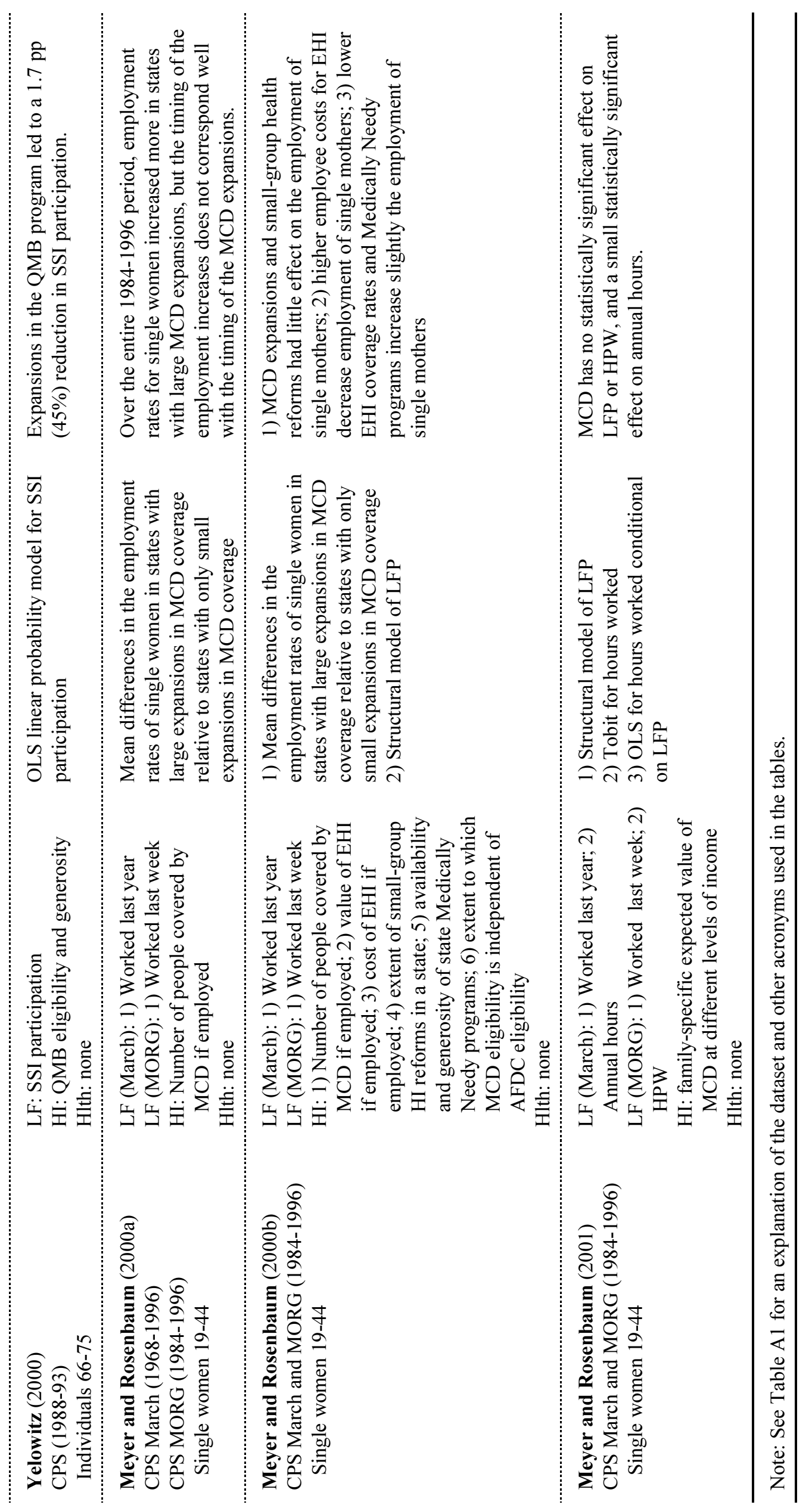




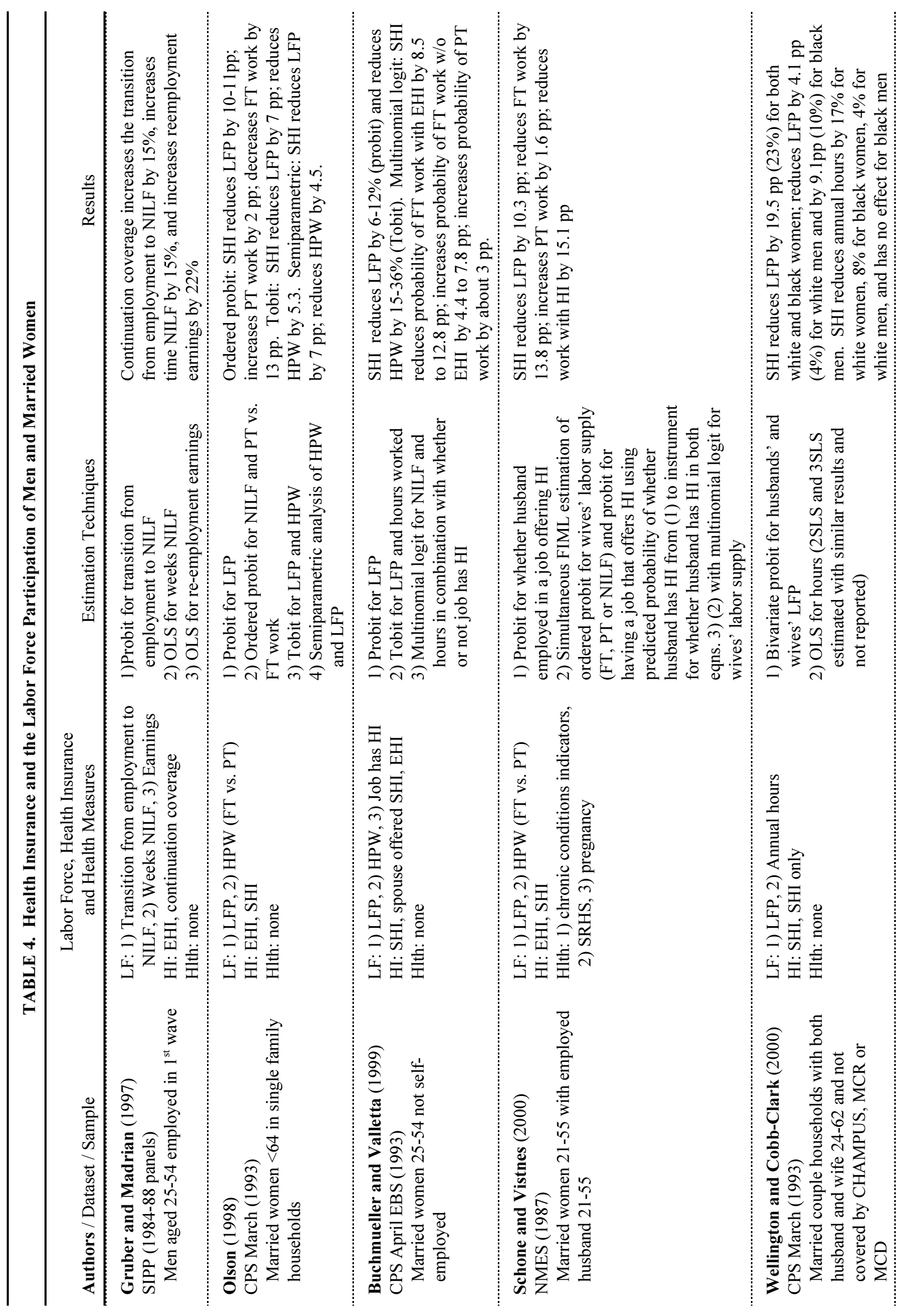




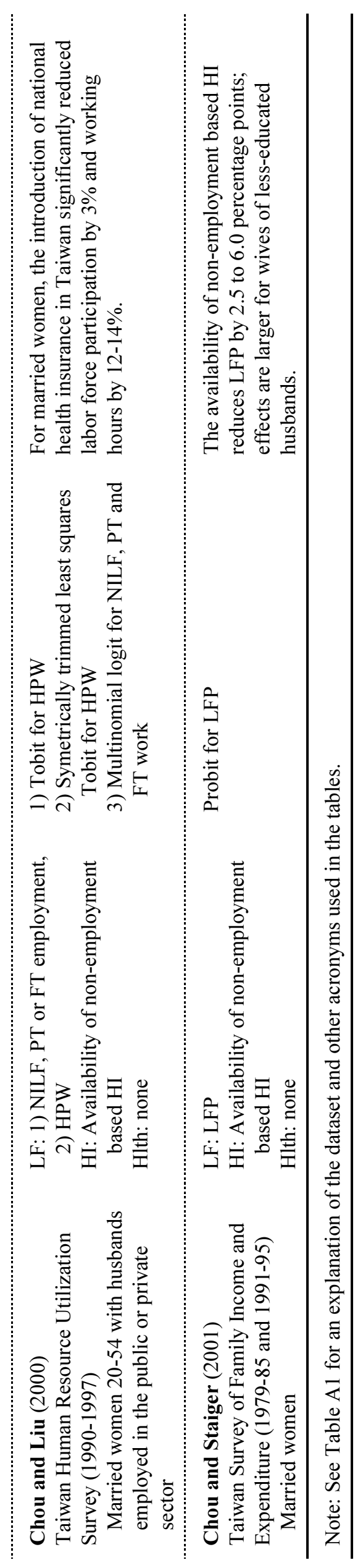




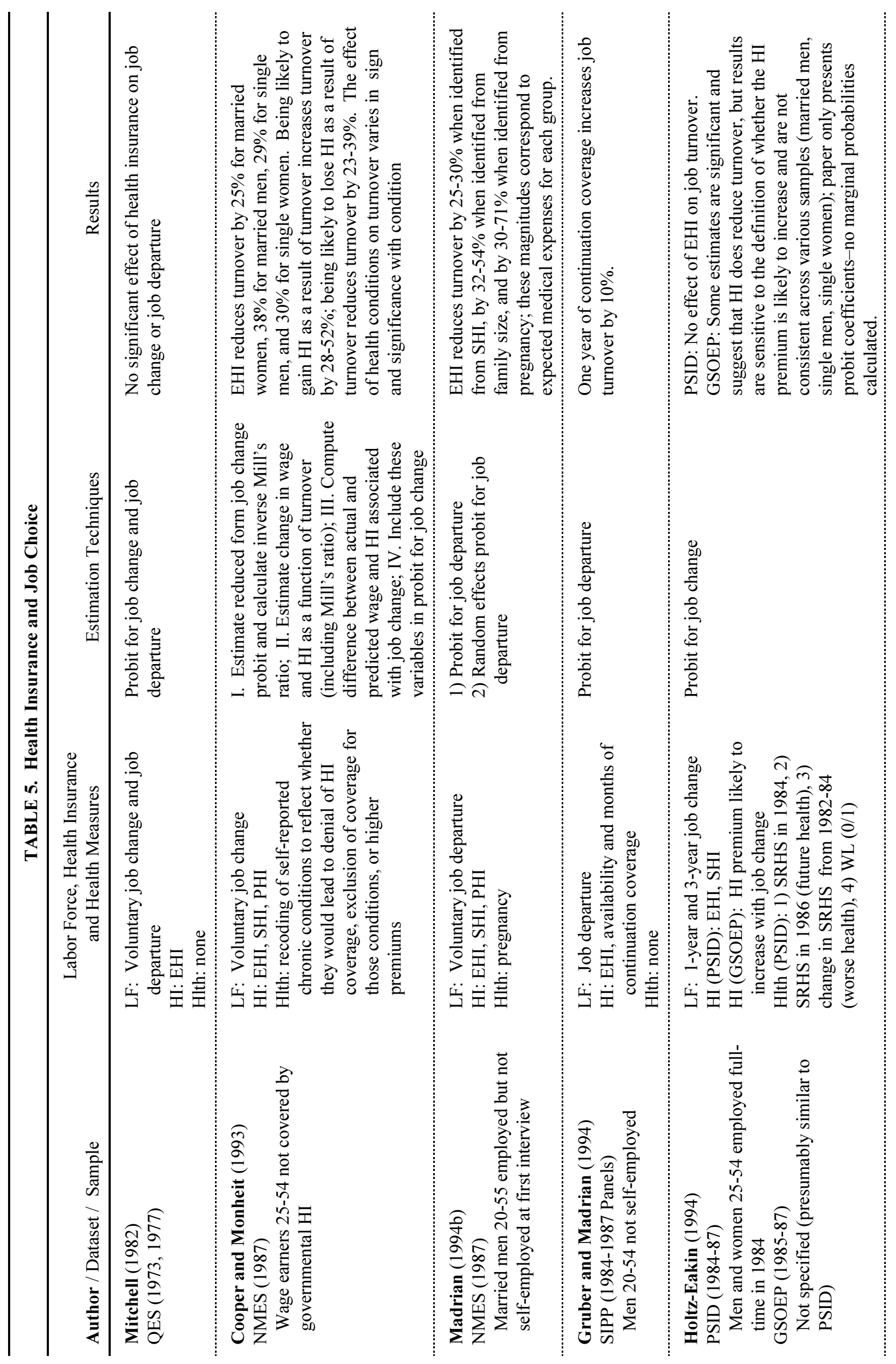




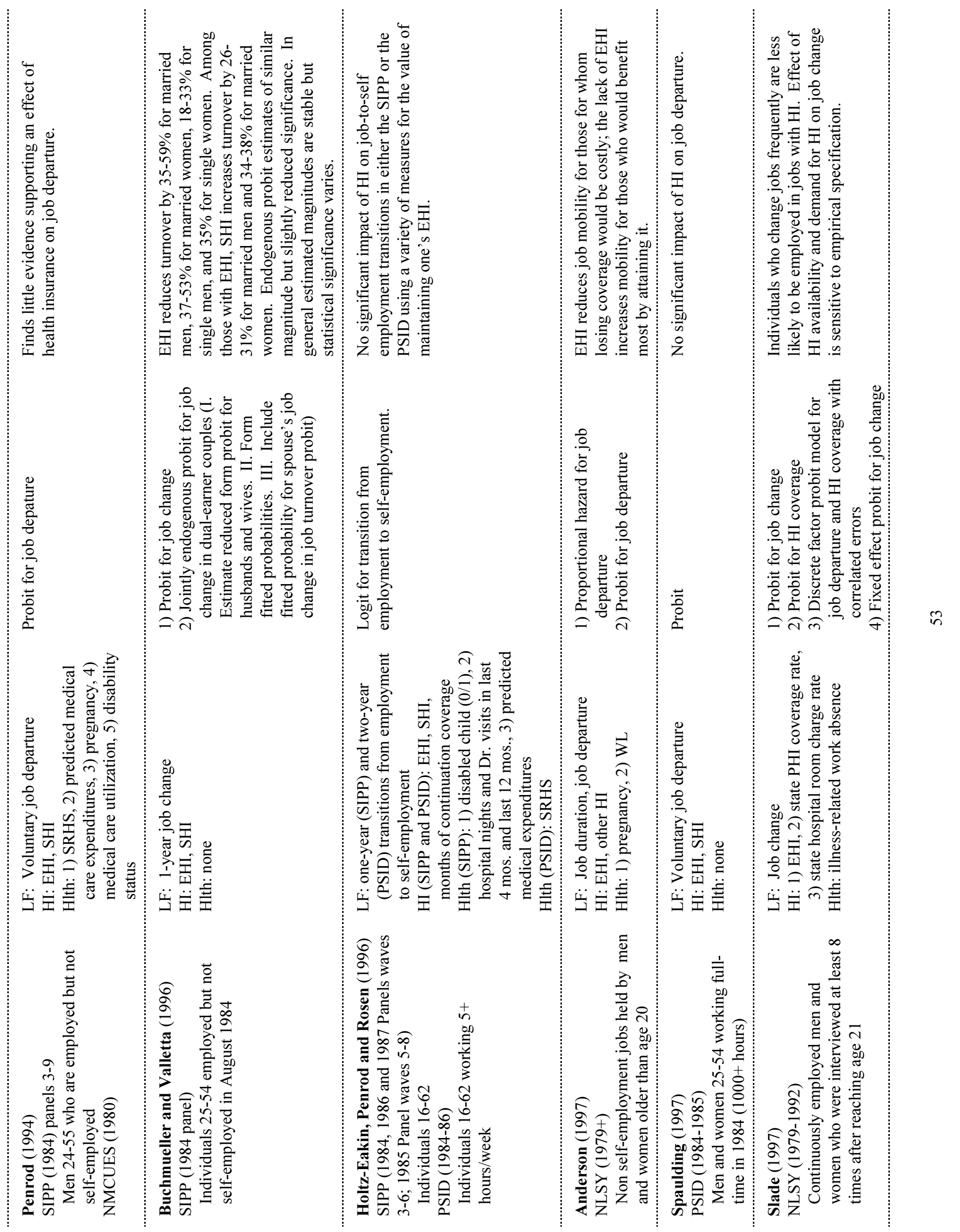




\begin{tabular}{|c|c|c|c|c|}
\hline 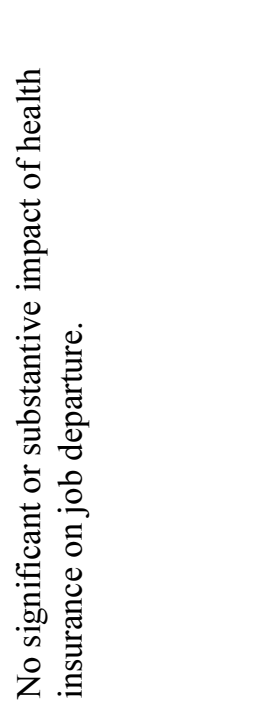 & 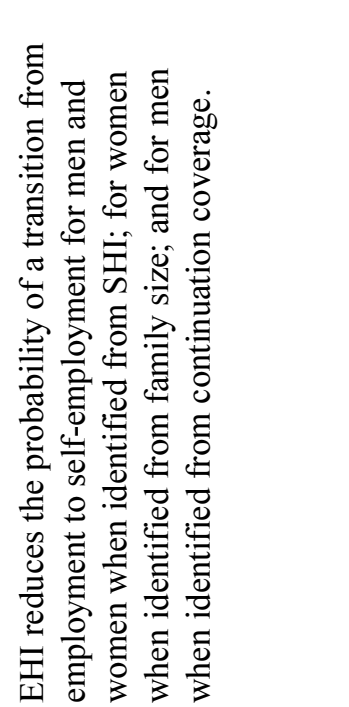 & 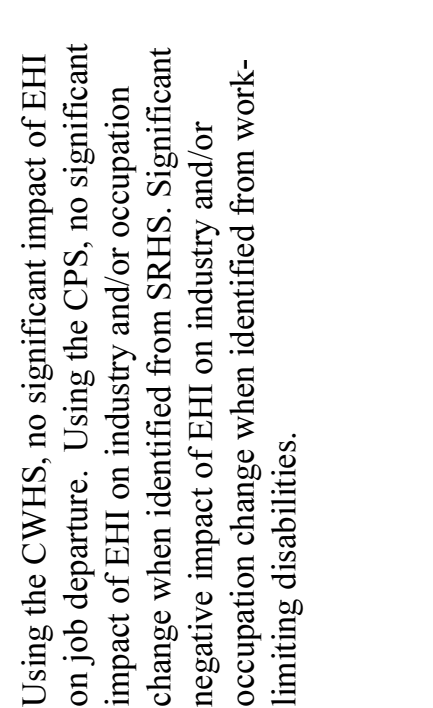 & 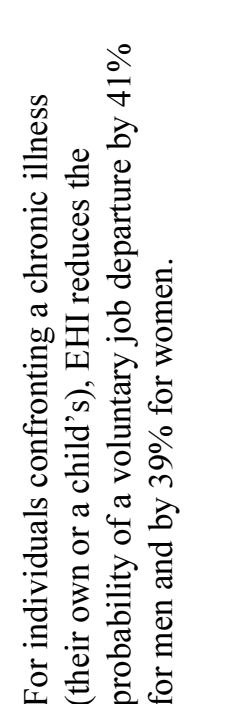 & 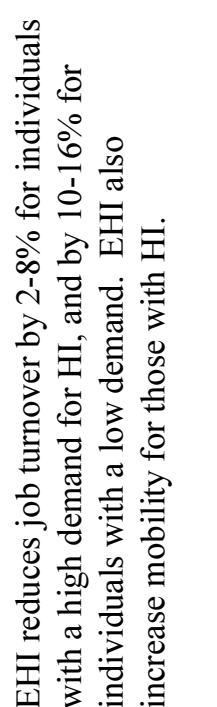 \\
\hline 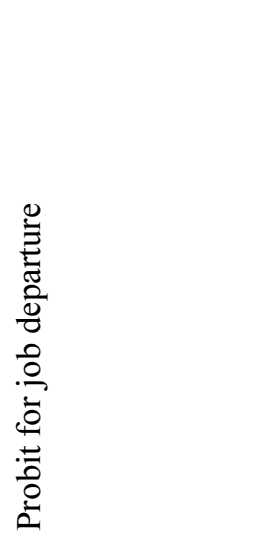 & 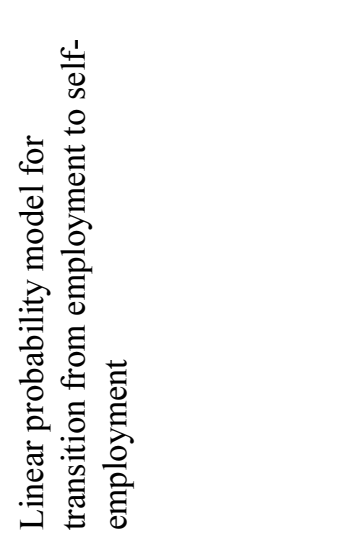 & 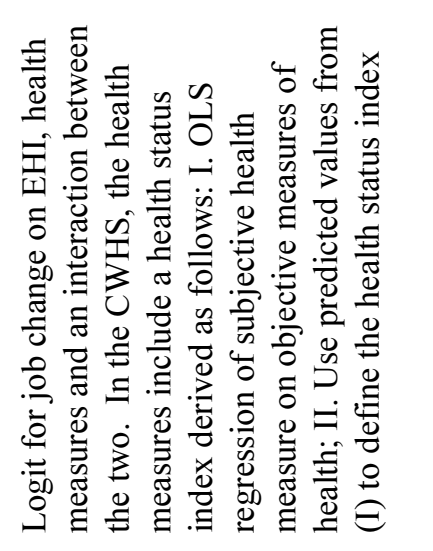 & 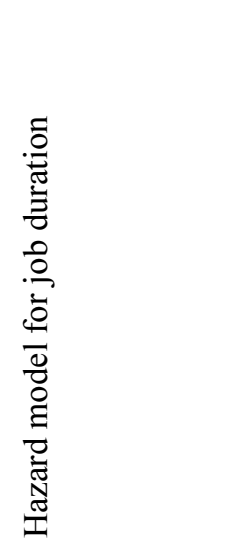 & 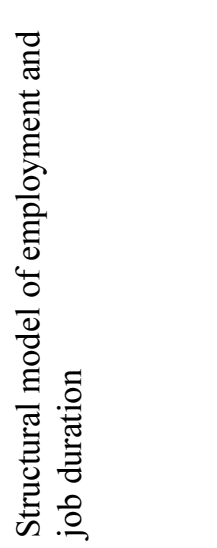 \\
\hline 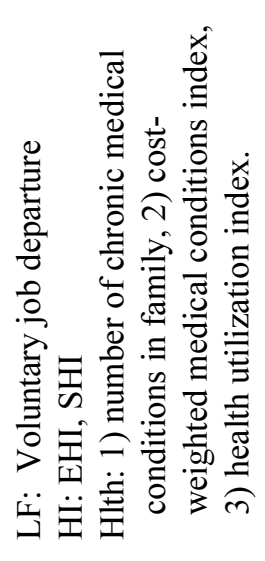 & 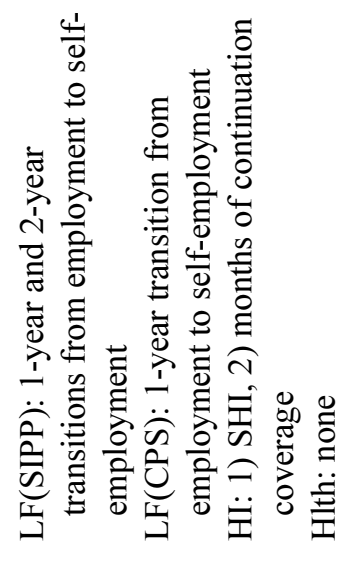 & 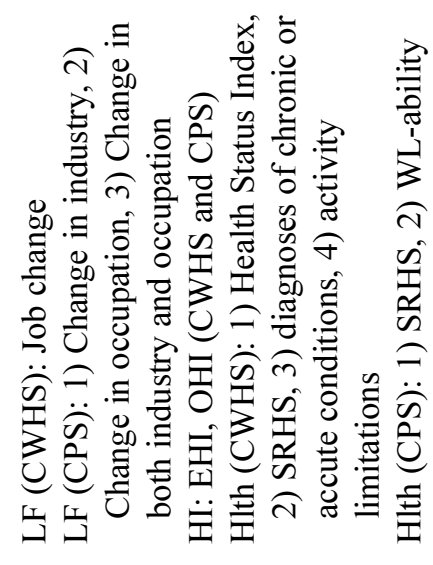 & 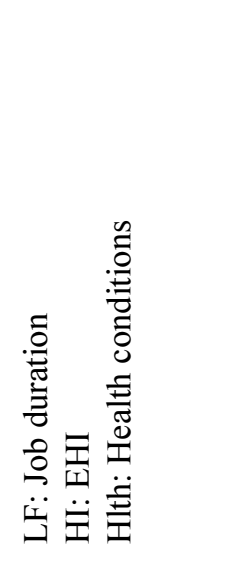 & 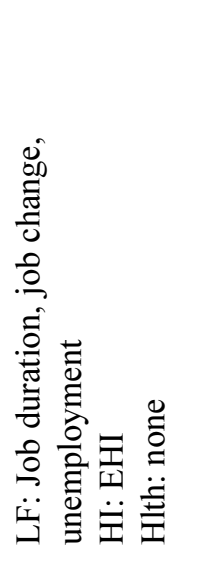 \\
\hline 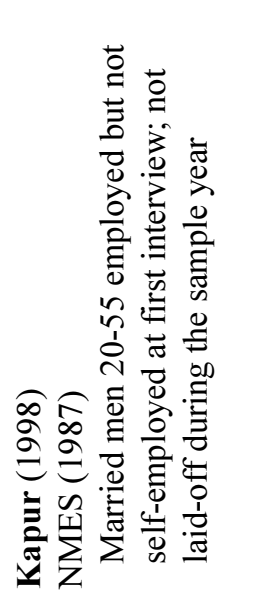 & 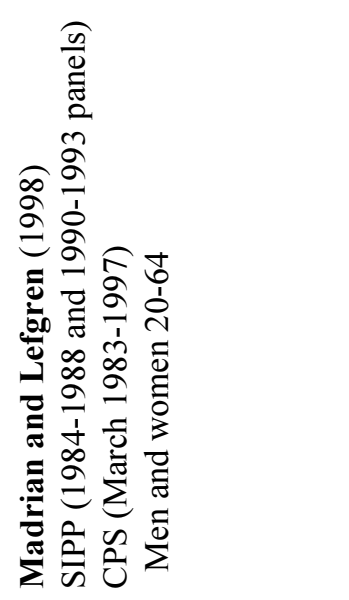 & 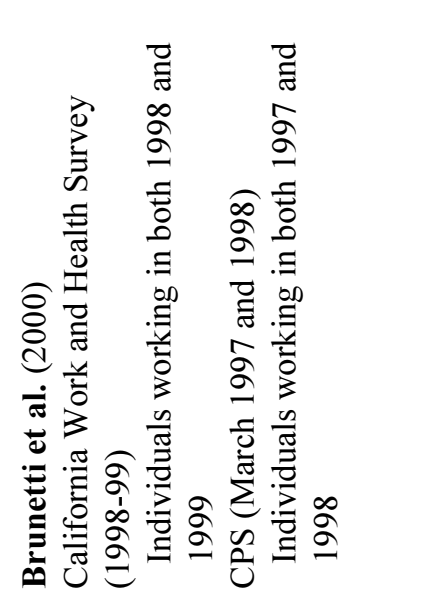 & 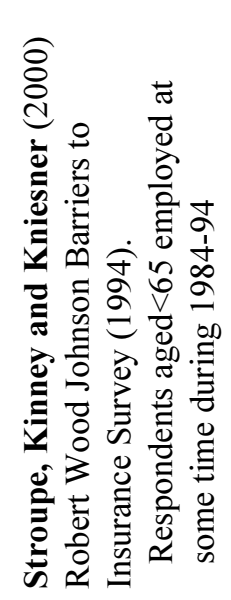 & 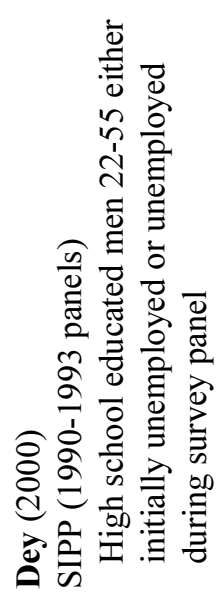 \\
\hline
\end{tabular}




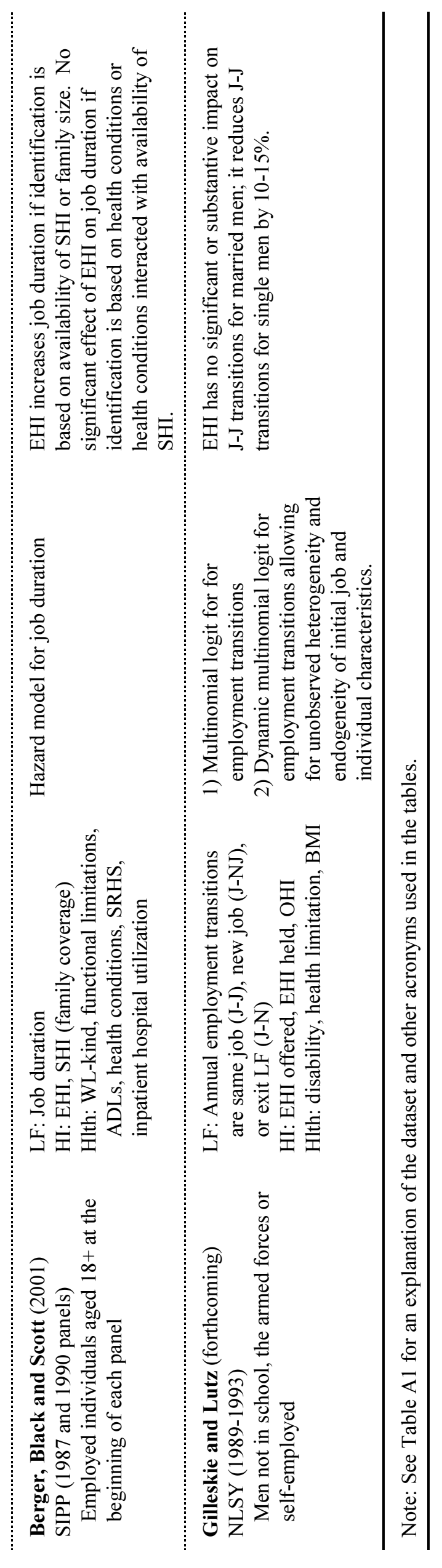


TABLE 6. Summary Statistics on the Health Insurance and Labor Market Outcomes Literature

\begin{tabular}{|c|c|c|c|c|c|c|c|c|}
\hline & \multicolumn{2}{|c|}{$\begin{array}{l}\text { LFP of Older Adults } \\
\text { (Table 2) }\end{array}$} & \multicolumn{2}{|c|}{$\begin{array}{c}\text { LFP of Single } \\
\text { Mothers (Table 3) }\end{array}$} & \multicolumn{2}{|c|}{$\begin{array}{l}\text { LFP of Men/Married } \\
\text { Women (Table 4) }\end{array}$} & \multicolumn{2}{|c|}{$\begin{array}{l}\text { Job Choice } \\
\text { (Table 5) }\end{array}$} \\
\hline & Number & Fraction & Number & Fraction & Number & Fraction & Number & Fraction \\
\hline Number of studies & 16 & {$[100 \%]$} & 16 & {$[100 \%]$} & 7 & {$[100 \%]$} & 18 & {$[100 \%]$} \\
\hline Published in refereed journal & 7 & {$[44 \%]$} & 9 & {$[56 \%]$} & 4 & {$[57 \%]$} & 9 & {$[50 \%]$} \\
\hline Published elsewhere & 3 & {$[19 \%]$} & 1 & {$[6 \%]$} & 1 & {$[14 \%]$} & 1 & {$[6 \%]$} \\
\hline Working paper/dissertation & 6 & {$[38 \%]$} & 6 & {$[38 \%]$} & 2 & {$[29 \%]$} & 8 & [44\%] \\
\hline \multicolumn{9}{|l|}{ Datasets used $^{\mathrm{a}}$} \\
\hline CPS & 3 & {$[19 \%]$} & 9 & {$[56 \%]$} & 3 & {$[43 \%]$} & 1 & {$[6 \%]$} \\
\hline SIPP & 3 & {$[19 \%]$} & 3 & {$[19 \%]$} & 1 & {$[14 \%]$} & 7 & [39\%] \\
\hline PSID & 0 & {$[0 \%]$} & 0 & {$[0 \%]$} & 0 & {$[0 \%]$} & 3 & {$[17 \%]$} \\
\hline Census & 1 & {$[6 \%]$} & 0 & {$[0 \%]$} & 0 & {$[0 \%]$} & 0 & {$[0 \%]$} \\
\hline RHS & 2 & {$[13 \%]$} & 0 & {$[0 \%]$} & 0 & {$[0 \%]$} & 0 & {$[0 \%]$} \\
\hline HRS & 7 & [44\%] & 0 & {$[0 \%]$} & 0 & {$[0 \%]$} & 0 & {$[0 \%]$} \\
\hline NMCUES or NMES & 1 & {$[6 \%]$} & 2 & {$[13 \%]$} & 1 & {$[14 \%]$} & 3 & {$[17 \%]$} \\
\hline NLSY & 0 & {$[0 \%]$} & 1 & {$[6 \%]$} & 0 & {$[0 \%]$} & 3 & {$[17 \%]$} \\
\hline Other & 1 & {$[6 \%]$} & 3 & {$[19 \%]$} & 2 & {$[29 \%]$} & 4 & {$[22 \%]$} \\
\hline \multicolumn{9}{|l|}{ Sample } \\
\hline Men only & 11 & {$[69 \%]$} & 0 & {$[0 \%]$} & 1 & {$[14 \%]$} & 6 & {$[33 \%]$} \\
\hline Women only & 0 & {$[0 \%]$} & 16 & {$[100 \%]$} & 5 & {$[71 \%]$} & 0 & {$[0 \%]$} \\
\hline Men and women & 5 & [31\%] & 0 & {$[0 \%]$} & 1 & {$[14 \%]$} & 12 & {$[66 \%]$} \\
\hline \multicolumn{9}{|l|}{ Estimation technique } \\
\hline Reduced form & 10 & {$[63 \%]$} & 15 & {$[94 \%]$} & 7 & {$[100 \%]$} & 17 & [94\%] \\
\hline Structural & 6 & {$[38 \%]$} & 1 & {$[6 \%]$} & 0 & {$[0 \%]$} & 3 & {$[17 \%]$} \\
\hline \multicolumn{9}{|l|}{ Characterization of results ${ }^{\mathrm{b}}$} \\
\hline "Positive" and significant & 12 & {$[75 \%]$} & 8 & {$[50 \%]$} & 7 & {$[100 \%]$} & 6 & {$[33 \%]$} \\
\hline Insignificant & 1 & {$[6 \%]$} & 3 & {$[19 \%]$} & 0 & {$[0 \%]$} & 6 & {$[33 \%]$} \\
\hline "Negative" and significant & 0 & {$[0 \%]$} & 0 & {$[0 \%]$} & 0 & {$[0 \%]$} & 0 & {$[0 \%]$} \\
\hline Mixed & 2 & {$[13 \%]$} & 5 & {$[31 \%]$} & 0 & {$[0 \%]$} & 5 & {$[28 \%]$} \\
\hline Unable to evaluate & 1 & {$[6 \%]$} & 0 & {$[0 \%]$} & 0 & {$[0 \%]$} & 1 & {$[6 \%]$} \\
\hline $\begin{array}{l}\text { a } \text { Use of multiple datasets in a st } \\
100 \% \text {. } \\
\text { b We characterize the results of } \\
\text { employment outcomes in the } \mathrm{w}\end{array}$ & $\begin{array}{l}\text { ly as " } p c \\
\text { edicted }\end{array}$ & otals that e & eed the $n$ & nber of st & es and pe & entages the & sum to mo & \\
\hline
\end{tabular}


TABLE A1. Dataset and Variable Acronyms

\begin{tabular}{|c|c|}
\hline Acronym & Dataset Name or Variable Definition \\
\hline \multicolumn{2}{|l|}{ Datasets } \\
\hline CPS & Current Population Survey \\
\hline CPS MORG & CPS Merged Outgoing Rotation Group \\
\hline GSOEP & German Socio-Economic Panel Survey \\
\hline HRS & Health and Retirement Study \\
\hline NLSY & National Longitudinal Survey of Youth \\
\hline NMCES & National Medical Consumption and Expenditure Survey \\
\hline NMCUES & National Medical Care Utilization and Expenditure Survey \\
\hline NMES & National Medical Expenditure Survey \\
\hline PSID & Panel Study on Income Dynamics \\
\hline QES & Quality of Empoyment Survey \\
\hline RHS & Retirement History Survey \\
\hline SIPP & Survey of Income and Program Participation \\
\hline \multicolumn{2}{|c|}{ Labor force variables } \\
\hline FT & Full-time employment \\
\hline HPW & Hours per week \\
\hline LFP & Labor Force Participation \\
\hline NILF & Not in the Labor Force \\
\hline PT & Part-time employment \\
\hline \multicolumn{2}{|c|}{ Health Insurance variables } \\
\hline EHI & Own employer-provided health insurance \\
\hline $\mathrm{HI}$ & Health insurance \\
\hline MCD & Medicaid \\
\hline MCR & Medicare \\
\hline NI & Not insured \\
\hline $\mathrm{OHI}$ & Other non-own-employer-provided health insurance \\
\hline PHI & Private Health Insurance \\
\hline QMB & Qualified Medicare Beneficiary \\
\hline RHI & Employer-provided retiree health insurance \\
\hline SHI & Spouse has employer-provided health insurance \\
\hline \multicolumn{2}{|c|}{ Health variables } \\
\hline ADL & Activities of Daily Living \\
\hline SRHS & Self-reported health status (excellent, good, fair, poor) \\
\hline WL & Work limitation \\
\hline
\end{tabular}




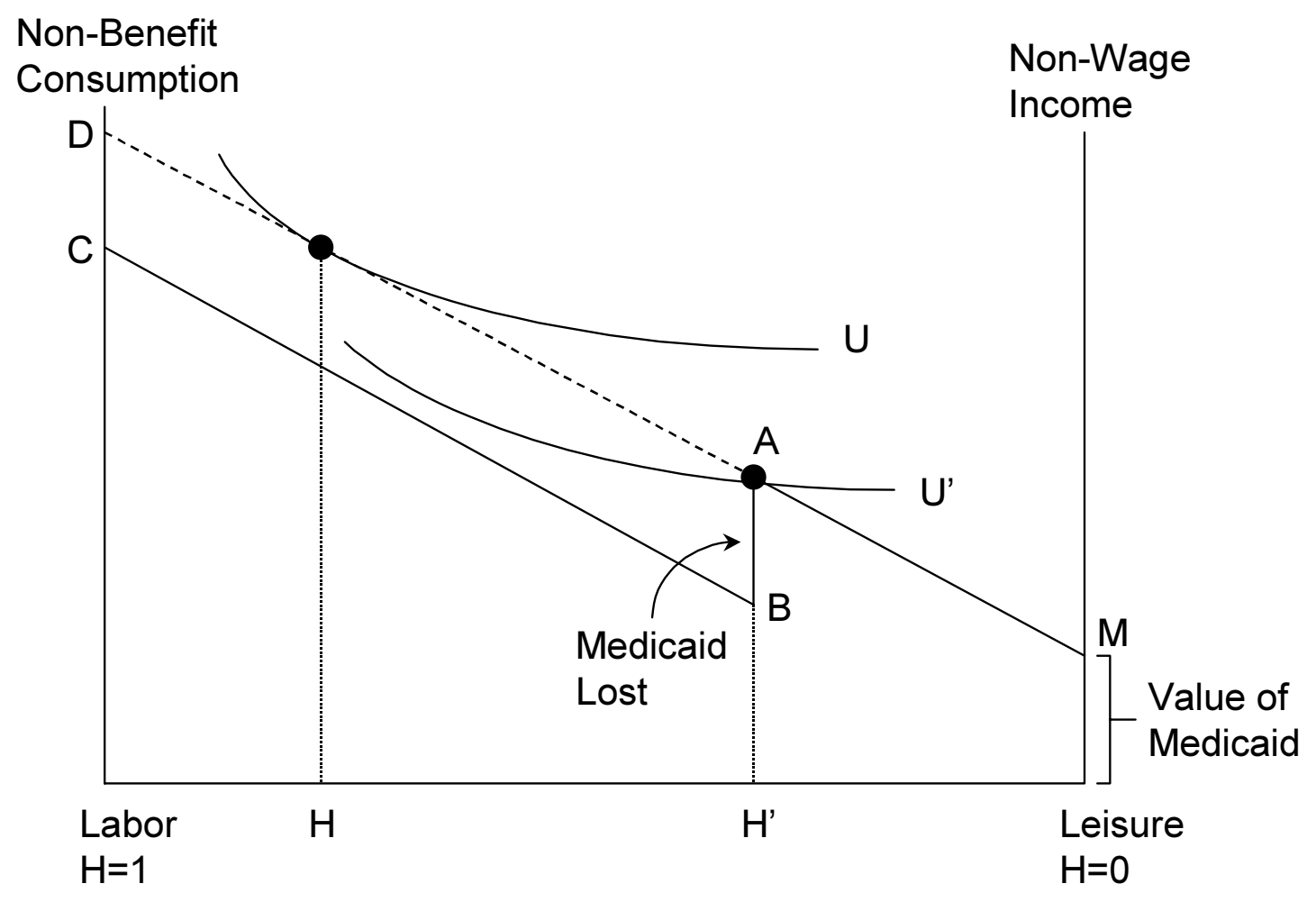

FIGURE 1 